\title{
Alfarería típica de San Pedro de Atacama (norte de Chile)
}

MYriam TARRAGó ${ }^{1}$

El presente artículo fue preparado para ser publicado en 1966 como introducción al trabajo "Secuencias culturales de la etapa agroalfarera de San Pedro de Atacama (Chile)", editado en 1968 en el volumen II de las Actas y Memorias del XXXVII Congreso Internacional de Americanistas de 1966.

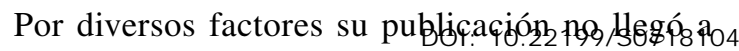
concretarse. Ahora, después de 10 años de nuestro estudio en San Pedro de Atacama se va a materializar en la serie Estudios Atacameños del Museo Arqueológico de esa localidad. Debo expresar mi complacencia y agradecimiento al editor por hacer posible la divulgación de este trabajo.

Corresponde, al mismo tiempo, hacer algunas observaciones con respecto al mismo. $\mathrm{Al}$ recibir el ofrecimiento de publicación se nos presentaban dos alternativas, o mantener el manuscrito original con las observaciones y resultados logrados hasta aquel momento o proceder a una revisión profunda dado el tiempo transcurrido y los trabajos de investigación efectuados posteriormente. Pero esta última alternativa nos implicaba, en realidad, efectuar un nuevo trabajo de investigación. Considerando las observaciones de otros colegas de que el trabajo aún mantiene su vigencia puesto que no se han efectuado luego otros trabajos de este tipo en la zona y de que en él hay datos descriptivos que pueden resultar útiles para otras investigaciones, nos inclinamos por la primera posibilidad. Hemos mantenido, por lo tanto, el manuscrito original con el manejo bibliográfico y de colecciones hasta la fecha ya indicada.

Cabe hacer otra anotación. El estudio de la alfarería funeraria fue encarado con un objetivo fundamentalmente cronológico ante la necesidad imperiosa de ordenar en fases la enorme riqueza de materiales existentes en el Museo Arqueológico con procedencia de los oasis de la zona. Para ello era necesario buscar todo dato intrínseco o por cronología cruzada que nos pudiera socorrer en el intento.

1 Universidad Nacional del Litoral, Rosario, ARGENTINA.
Por esas razones el trabajo muestra una tendencia a hacer comparaciones cerámicas con otras regiones, en especial el Noroeste Argentino como si, aparentemente, el proceso de cambio se redujera a las posibles vías de "difusión y contacto". En consecuencia, es posible que no se desprenda de él con toda su fuerza, el interesante proceso interno de desarrollo de las 1998.0604 dedefer aldeanas de San Pedro de Atacama, con características en gran medida autónomas en sus relaciones con el medio ambiente y el proceso económico y social cumplido, a pesar de haber observado estos hechos durante el estudio de las secuencias de tumbas. Su análisis es fundamental en esta nueva etapa de la arqueología del Area Andina Meridional y contribuirá a mejorar las interpretaciones sobre los procesos gestados en las diversas subáreas. El hecho de que la sociedad Tiahuanaco haya incidido en la vida de las comunidades de los oasis o de que se hayan dado contactos con los valles del Noroeste Argentino o de las selvas orientales, no es suficiente para comprender y explicar el proceso. Pero todo esto, por supuesto, debe ser objeto de otro tipo de trabajo.

Se puede señalar, no obstante, que estos hechos están expresados a nivel de la tecnología cerámica en el desarrollo de la alfarería negra pulida que es realmente una característica propia de la subárea y en la que, esas comunidades, dentro de la simpleza del estilo, lograron hermosos ejemplares exponentes de una vigorosa tradición que coexiste con fuerte predominio en las tumbas junto con ceramios importados de otras regiones vecinas.

Pasamos, después de estas necesarias aclaraciones, al estudio concreto de la alfarería. Intentaremos una descripción de la cerámica característica de San Pedro de Atacama, departamento del Loa, poniendo el acento en especial, en la cerámica negra pulida que es, como ya señalamos, la más típica. Su propósito es reunir y unificar los datos incluidos en las descripciones realizadas anteriormente (Latcham 1928, 1938; Le Paige 1957/58, 1963a; Montané 1963; Munizaga 1963; Orellana 1963a) incorporando en algunos casos otros detalles o nuevos criterios. 


\section{Trabajos anteriores sobre el tema y método de análisis}

Latcham $(1928,1938)$ hace una descripción bastante detallada de la alfarería atacameña pero, lamentablemente, confunde en un mismo grupo distintos tipos de variada procedencia, lo que impide que sus datos puedan utilizarse con seguridad en situaciones particulares, como en el caso de San Pedro de Atacama.

No obstante, es necesario destacar que incluye una serie de detalles en cuanto a técnicas de fabricación, formas y rasgos asociados que son importantes, más aún, por tratarse del primer intento de descripción.

Le Paige presenta los distintos tipos de alfarería característica de San Pedro de Atacama, haciendo hincapié en su comportamiento en las tumbas. En base a las asociaciones, ofrece un cuadro resumen de las secuencias organizadas en siete niveles (Le Paige 1963a:196-197). En su publicación de 1964 agrega otro aspecto, un resumen de las secuencias por cada sitio de cementerio. Con los descubrimientos del padre Le Paige se modifica profundamente el panorama del área atacameña. Individualiza sitios de vivienda y cementerios, exhuma numerosas tumbas y nuclea todo el material en el Museo Arqueológico, obra ésta de su esfuerzo personal que ha impedido que el valioso material extraído se disperse. Gracias a su empeño una de las más valiosas colecciones de los Andes Meridionales ha posibilitado diversos estudios, entre ellos el nuestro y, sin duda, muchos otros en el futuro.

Munizaga (1963) en base a un análisis exhaustivo de fragmentos cerámicos recolectados por él en el sitio de Coyo y a un estudio complementario de fragmentos recogidos por el padre Le Paige y depositados en el Museo, define en forma muy completa una serie de tipos cerámicos, en especial, los tipos incisos, pero establece otros con un número demasiado pequeño de fragmentos como para tener la certeza que representan tipos reales que han funcionado como tales en San Pedro. Esto no implica que no puedan adquirir validez en análisis de muestras más grandes.

Orellana (1963a y b) describe el tipo cerámico San Pedro Rojo Pulido que no había sido definido con anterioridad y propone el empleo del criterio del sitio tipo para la denominación de los tipos cerámicos de San Pedro de Atacama, lo que fue aceptado en el Congreso Internacional de Arqueología reunido en esa localidad en 1963. Aplicaremos aquí este mismo criterio.

Montané (1963) precisa la descripción de la "alfarería negra pulida" con sus rasgos más importantes e introduce una novedad: postula la no existencia de engobe y la utilización de atmósfera oxidante y luego reductora en la cocción. Con respecto a la primera afirmación, nosotros sugerimos otra técnica en el acabado de la superficie, de acuerdo con los análisis efectuados por el Dr. César Cortelezzi (ver Apéndice).

Para nuestra descripción tomamos la colección de piezas cerámicas completas depositadas en el Museo de San Pedro de Atacama hasta noviembre de 1964 y que proceden de los cementerios de la zona. El hecho de que se trata de alfarería funeraria limita nuestro análisis al impedirnos alcanzar la popularidad y el comportamiento de los tipos con respecto al universo cerámico total. Necesitaríamos incorporar la alfarería exhumada de viviendas y basureros. Sólo futuras excavaciones podrán incorporar estas dos últimas categorías de datos. Hasta este momento, por dificultades mismas del terreno, no se han realizado excavaciones lo suficientemente completas como para proporcionar datos diagnósticos en ese sentido. Sin embargo, a pesar de esta limitación, el estudio de la distribución y proporción relativa de la alfarería funeraria típica por sitio de enterramiento puede brindar una serie de datos de interés para futuros trabajos de afinamiento de las secuencias y las causas de las modificaciones en las tradiciones alfareras.

En primer lugar, debemos deslindar lo que entendemos por alfarería característica de San Pedro como conjunto coherente, con unidad interna, frente a los casos aislados representados por las vasijas cerámicas excepcionales. Nos hemos guiado por el número de ejemplares y frecuencias de apariciones para luego establecer las diferencias de pasta, antiplástico, manufactura, superficie, forma y decoración entre la cerámica que consideramos propia de San Pedro y la que resulta extraña al área por su tipo y por su comportamiento en las tumbas. Nos referiremos aquí sólo a las del primer grupo, con un enfoque casi exclusivamente morfológico. El tratamiento del aspecto espacial y temporal se desarrolla en extensión en otro artículo (Tarragó 1968). 
El estudio morfológico de los tipos lo hemos llevado a cabo tomando como guía para el análisis y ordenación: las "normas de descripción de tipos cerámicos" aprobadas en la I Convención Nacional de Antropología reunida en Córdoba, Argentina, en mayo de 1964 (1966) con los complementos de Serrano (1952) y Nimo (1946), además de Ford (1962) y Heizer (1959), entre otros. Para la definición de las formas hemos aplicado los criterios geométricos propuestos por Shepard (1963), porque consideramos que es la única forma objetiva, hasta este momento, de poder alcanzar una unificación en cuanto a forma que, como rasgo, es muy importante en el análisis estructural y para fines comparativos. La disparidad de criterios utilizados hasta el presente es tan grande que se presta a todo tipo de confusiones y diferentes interpretaciones. Esta investigadora parte para la elaboración de su sistema de un principio simple: la definición de los puntos característicos del perfil de una vasija que determinan los cambios en la línea del contorno, puntos terminales, puntos de tangencia vertical, puntos angulares y puntos de inflexión. A esta primera distinción agrega un nuevo aspecto, si se trata de vasijas de boca restringida o no y, dentro de las vasijas de boca constreñida, si son dependientes o independientes. De esta manera evita el problema de la existencia o no de un cuello, determinación que se basaba meramente en las proporciones. Es mucho más importante, como sostiene Shepard, la existencia o no de un punto de inflexión o de un punto angular por encima del diámetro máximo de la vasija, ya que, con esa sola especificación, estamos indicando que se produce un cambio en el contorno que supone, en consecuencia, un cambio de forma. Esto se completa con el cálculo de la relación entre las alturas y los diámetros de los dos sectores. Tomemos un ejemplo de la cerámica negra pulida. En la Forma X (Figura 8) observamos que de una forma ovoide erecta pasa el contorno mediante un punto angular a una forma subcilíndrica en el sector superior. Esta última forma representa el cuello en el sentido tradicional con una relación entre la altura del cuello y la altura del cuerpo de 0.4. Con estos criterios, fácilmente aplicables en cada vasija entera $\mathrm{y}$ factibles de control cuantas veces se desee y por distintas personas, llega Shepard a la formulación de cuatro clases de contornos. Las formas simples tienen sólo puntos terminales o puntos terminales $y$ un punto de tangencia vertical. Las formas compuestas se caracterizan por un ángulo que marca la unión neta de dos partes de la vasija de distinta forma. Las vasijas inflexionadas presentan superficies convexas y cóncavas unidas por una curva suave, es decir, mediante un punto de inflexión. Los contornos complejos poseen dos o más puntos angulares y/o de inflexión que marcan varios cambios de formas. $\mathrm{La}$ definición se completa con el agregado de las formas geométricas que reproducen las distintas partes de la vasija y el cálculo de las diversas relaciones entre proporciones, entre altura y diámetro, entre diámetros, entre alturas, etc. El sistema propuesto por Shepard, con la aplicación de criterios objetivos, se convierte en un instrumento muy útil para el análisis, en especial, cuando se trabaja con vasijas completas y muestras grandes y se procura definir tipos.

Con respecto al comportamiento de los tipos por sitio de enterramiento, hemos intentado inferirlo por dos métodos, uno gráfico (Ford 1962) y uno estadístico de test de significación $\left(x^{2}\right)$, además de las correlaciones con los resultados obtenidos por el método de seriación de tumbas (Tarragó 1968: 124-126).

El total de vasijas que analizamos en este trabajo asciende a 2347 ejemplares enteros, con procedencia de 17 sitios de enterramiento de los alrededores del pueblo actual: Tulor, Poconche, Beter, Tchaputchayna, Coyo, Solor 3 Túmulo Norte-Sur, Solor 3, Parte Occidental del Túmulo Norte, Tchecar Norte, Sequitor Oriental, Sequitor Acequia, Larache Callejón, Larache Acequia, Quitor 8, Quitor 7, Quitor 2, Quitor 6, Quitor 5. En ese total se encuentran representados varios tipos cerámicos, de los cuales describiremos en extensión, dado el espacio con que contamos, los tipos San Pedro de Atacama Rojo Pulido, Negro Pulido, Rojo Grabado y Negro Grabado.

Las descripciones van precedidas de una reseña donde enumeramos las principales características de cada tipo. A la izquierda de cada ítem de las descripciones incluimos un intento de codificación decimal con el objeto que permita una tabulación si se desea en el futuro.

\section{Alfarería negra pulida de San Pedro de Atacama}

Este tipo cerámico se caracteriza por presentar una pasta fina, superficies negras bruñidas y un predominio de formas simples de tamaño mediano (jarros cilíndricos, escudillas semiesféricas y vasos troncocónicos y ovoides). El único intento decorativo se da en botellones de cuello alto por medio de incisiones y modelados. El motivo puede ser realista, 
con la representación de caras antropomorfas, o geométrico. El negro pulido es el tipo más popular y representativo de la cerámica funeraria de los oasis de San Pedro de Atacama.

0. Nombre: San Pedro de Atacama Negro Pulido

1. Otros nombres

"Alfarería negra pulimentada atacameña" (Latcham 1928), "Cerámica negra pulida atacameña clásica" (Le Paige 1963a: 12), "San Pedro de Atacama negro pulido" (Le Paige 1964: 53), "Alfarería negra pulida de San Pedro de Atacama" (Montané 1963). La denominación que se adopta es la propuesta por Orellana (1963a) y utilizada por Munizaga (1963) y Núñez (1965).

2. Procedencia: San Pedro de Atacama

Lugares: Quitor 5, 6, 2, 8, 7; Larache Acequia y Larache Callejón; Sequitor Acequia y Sequitor Oriental; Tchecar Norte; Solor 3, Parte Occidental del Túmulo Norte y Solor 3, Túmulo Norte-Sur; Coyo, Tchaputchayna, Beter, Poconche, Tulor.

3. Sitio tipo: San Pedro de Atacama

4. Número de ejemplares de la muestra: 1929 (Cuadro 1).

5. Pasta

\subsection{Antiplástico:}

5.1.0. Composición. Plagioclasas, ortosa, cuarzo, hornblenda, escasas láminas de biotita y gránulos de óxido de hierro. Todos los fragmentos son angulosos (ver Apéndice, muestras 1 y 2).

\subsubsection{Tamaño:}

\subsection{Uniforme.}

5.1.1.1.1. Fino: $1 \mathrm{~mm}$ el tamaño mayor, tamaño medio 253 micrones (ver Apéndice).

5.1.2.0. Distribución: Regular.

5.1.3.0. Densidad: Denso.

\subsection{Textura.}

5.2.0.0.0. Uniforme.
5.2.0.1.1. Fina.

5.2.0.2.0. Regular.

\subsection{Densa.}

5.2.1.0./1. Compacta a laminar. En casi todos los casos tendencia a laminarse.

\subsection{Fractura.}

5.3.0./1. De irregular a regular angular.

5.4. Color: Centro del núcleo: negro a pardo. Partes adyacentes a la superficie: negra.

6. Manufactura

Es posible que se haya empleado el modelado directo como lo sugiere Munizaga (1963: 113) y la técnica por rodete.

7. Superficie

7.0. Color: Negra (externa e interna).

7.1. Dureza: 4 a 4.5 (escala de Mohs).

7.2. Regularidad: En relación con el trabajo realizado por el instrumento pulidor. Es regular hasta donde alcanzó éste.

7.2.0. Regular: En la superficie externa y en la superficie interna de las vasijas no restringidas, forma II, IV y I.

7.2.1. Irregular: En la superficie interna de vasijas de boca constreñida.

7.3. Tratamiento: Pulimento en la superficie externa y en la interna, en las vasijas de boca no restringida, forma III y IV, con un instrumento muy regular en dirección horizontal. Las estrías de pulimento son muy tenues y la superficie muy uniforme. Se observa, además, un traslado del antiplástico hacia el centro del núcleo, lo que determina una capa superficial distinta del núcleo que, en algunos casos, se desprende como si no existiera mucha afinidad entre ambas (ver Apéndice, muestras 1 y 2).

7.4. Baños: Montané (1963: 45) afirma que no existe engobe oponiéndose a lo sostenido por Latcham $(1928,1938)$ en el sentido de la aplicación de 
un enlucido o barniz. El análisis de una muestra de cerámica negra pulida ha permitido determinar que sobre la superficie se agregó hematita, variedad especularita, en forma de capas, lo que le confirió a aquélla, junto con el pulido, el color negro homogéneo de brillo metálico. El Dr. Cortelezzi estima que la hematita puede haber sido agregada sobre el bizcocho y empastada con agua y quizá algo de bórax como ligante (ver Apéndice, muestras 1 y 2).

7.5. Defectos: En algunos casos se observan diferencias de color por deficiencias de cocción, pero, en general, asombra la regularidad con que se ha logrado la cocción. Muchos ejemplares presentan sus superficies cuarteadas por la acción de agentes naturales.

\section{Cocción}

\subsubsection{Reductora.}

\subsubsection{Cocida.}

8.2.2./1. Uniforme, sólo en algunos casos irregular. Munizaga afirma al respecto, "Cocción: pareja, en ambiente reductor. El ennegrecimiento que estimamos corresponde a un ahumamiento intencional no permite ver en la pasta posibles regiones de diferente color"' (1963: 113). Montané (1963: 45) sostiene, en cambio, que este tipo cerámico fue sometido primero a un horno oxidante y luego a una atmósfera reductora lo suficientemente intensa como para producir una buena absorción de carbono.

\section{Forma}

La abundancia de especímenes de cerámica negra pulida nos permitió hacer un estudio detenido de las formas de contorno con sus elementos asociados, asas, base y borde, de acuerdo a los criterios dados por Shepard (1963).

Apliquemos estos criterios a nuestros casos. Hemos definido 10 formas de la cerámica negra pulida a las que agregamos tres formas raras, con muy escasa aparición, menos del $1 \%$ (Cuadro 1). Estableceremos, en lo posible, las equivalencias con las denominaciones tradicionales de formas cerámicas (jarros, escudillas, ollas, botellones) y con las definiciones dadas en otros trabajos.
9. I. Vasijas simples, de boca no restringida, cilíndricas.

Estamos en presencia de un caso especial de las formas simples, las cilíndricas, como lo señala Shepard, que tienen dos puntos terminales e infinitos puntos de tangencia vertical por tratarse de un cilindro (Figura 1). Todos los ejemplares tienen base plana y un asa en arco doble adherida, vertical. Coincide por todas sus características con el concepto de "jarro". Número de vasijas: 199 (10.31\% sobre un total de 1929) (Figura 2).

\subsection{Tamaño. ${ }^{2}$}

9.0.0.0. Altura de la pieza: $166 \mathrm{~mm}$.

9.0.0.2. Altura de las asas: $60 \mathrm{~mm}$.

9.0.1. Diámetro máximo: $95 \mathrm{~mm}$.

Relación entre altura y diámetro máximo:

$$
\frac{166}{95}: 1.7
$$

Equivaldría a la forma cilíndrica de Latcham (1928: figs. 18 y 32a, b, d, f; 1938: 245) y a la forma I de Munizaga (1963: 115); "vaso recto con un asa gruesa lateral vertical" (Le Paige 1964: 57 y 72; Orellana 1962a).

9. II. Vasos simples, restringidos, subcilíndricos (paredes ligeramente convergentes). Número de vasijas: 173 (8.96\%) (Figura 3).

\subsection{Tamaño.}

9.0.0.0. Altura de la pieza: $175 \mathrm{~mm}$.

9.0.0.2. Altura de las asas: $80 \mathrm{~mm}$.

9.0.1. Diámetro máximo: $100 \mathrm{~mm}$.

Relación entre altura y diámetro máximo:

$$
\frac{175}{100}: 1.75
$$

Corresponde a la forma publicada por Le Paige (1964: 204, lám. 108) y a la de Latcham (1928: 113, fig. 22).

\footnotetext{
2 Para el cálculo de tamaño se tomaron muestras no probabilísticas. Las medidas que se incluyen en los distintos tipos cerámicos son las medidas aritméticas calculadas en base a esas muestras.
} 
9. III. Vasos simples (con sólo puntos terminales), no restringidos, tronco-cónicos invertidos.

Número de vasijas: 382 (19.80\%). Es la forma que concentra el mayor número de casos (modo) (Figura 4).

\subsection{Tamaño.}

9.0.0.0. Altura de la pieza: $145 \mathrm{~mm}$.

9.0.0.2. Altura de las asas: $60 \mathrm{~mm}$.

9.0.1. Diámetro máximo, coincide con el diámetro de la boca: $90 \mathrm{~mm}$.

Relación entre altura y diámetro máximo:

$$
\frac{145}{90}: 1.6
$$

Esta forma corresponde a "los de forma de cono truncado" de Latcham (1928: 113; 1938: 245, figs. 19 y 65) y entrarían dentro del grupo 3 de Munizaga (1963: 115).

9. IV. Escudillas o pucos simples, restringidos o no restringidos, sección de esfera, con dos puntos terminales y un punto de tangencia vertical que coincide con el borde en las hemisféricas.

Número de vasijas: 246 (12.57\%) (Figura 5).

\subsection{Tamaño}

9.0.0.0. Altura de la pieza: $70 \mathrm{~mm}$.

9.0.0.2/3. Altura de las asas-apéndices: $60 \mathrm{~mm}$.

9.0.1. Diámetro máximo: $145 \mathrm{~mm}$.

Relación entre altura y diámetro:

$$
\frac{70}{145}: 0.48
$$

Relación entre altura del diámetro máximo y altura total:

$$
\frac{69}{70}: 0.98
$$

Equivaldría al tipo de plato de Latcham (1928: 112, figs. 1 a 8 ).
9. V. Vasijas simples, no restringidas, hiperboloides.

Con dos puntos terminales y un punto de tangencia vertical interno. Se trata de jarros de base plana y un asa en arco, doble adherida, vertical. Número de vasijas: $32(1.65 \%)$.

\subsection{Tamaño.}

9.0.0.0. Altura de la pieza: $125 \mathrm{~mm}$.

9.0.0.2. Altura del asa: $55 \mathrm{~mm}$.

9.0.1. Diámetro máximo: $65 \mathrm{~mm}$.

Relación entre altura y diámetro:

$\frac{125}{65}: 1.9$

Esta forma correspondería a la forma de la figura 31 de Latcham 1928: 113).

9. VI. Vasijas inflexionadas, restringidas, ovoide erecto (cuerpo), hiperboloide (cuello).

Semejan botellones sin asas. Número de vasijas: $15(0.77 \%)$.

\subsection{Tamaño.}

9.0.0.0. Altura de la pieza: $190 \mathrm{~mm}$.

9.0.0.1. Altura del punto de inflexión: $125 \mathrm{~mm}$.

9.0.1. Diámetro máximo: $150 \mathrm{~mm}$.

Relación entre altura y diámetro: 190

$$
\frac{190}{150}: 1.26
$$

Relación entre altura dcl cuello y altura del cuerpo:

$$
\frac{75}{125}: 0.6
$$

Variación: En tres ejemplares (0.15\%), la segunda forma es cilíndrica. Por sus proporciones no llega a ser un cuello sino un borde alto.

9. VII. Vasos simples, restringidos, sección de ovoide erecto, con uno o dos puntos terminales, un punto de tangencia vertical. Número de vasijas: 327 (15.95\%) (Figura 6). 
9.0. Tamaño.

9.0.0.0. Altura de la pieza: $90 \mathrm{~mm}$.

9.0.0.2/3. Altura de las asas-apéndices: $40 \mathrm{~mm}$.

9.0.1. Diámetro máximo: $110 \mathrm{~mm}$.

Relación entre altura y diámetro máximo:

$$
\frac{90}{110}: 0.8
$$

Corresponde aproximadamente a las formas publicadas por Latcham (1928: 112 y 115, figs. 9 y 52). Le Paige (1964: 203, lám. 107), publica un ejemplar típico.

9. VIII. Vasijas inflexionadas, restringidas, esferoides o subesferoides (cuerpo), cuello cilíndrico.

Se trata de botellones con el cuello proporcionalmente más bajo que en la forma VI. Número de vasijas: $41(2.12 \%)$.

\subsection{Tamaño.}

9.0.0.0. Altura de la pieza: $190 \mathrm{~mm}$.

9.0.0.1. Altura del punto de inflexión: $150 \mathrm{~mm}$.

9.0.0.2. Altura de las asas: $89 \mathrm{~mm}$.

9.0.1. Diámetro máximo: $185 \mathrm{~mm}$.

Relación entre altura y diámetro:

$$
\frac{190}{185}: 1.02
$$

Relación entre altura del cuello y altura del cuerpo:

$$
\frac{40}{150}: 0.26
$$

9. IX. Vasijas simples, restringidas, sección de elipsoide horizontal (escudillas).

Número de vasijas: 134 (6.94\%) (Figura 7)

\subsection{Tamaño.}

9.0.0.0. Altura de la pieza: $85 \mathrm{~mm}$. 9.0.0.2/3. Altura de las asas-apéndices: $47 \mathrm{~mm}$. 9.0.1. Diámetro máximo: $165 \mathrm{~mm}$.
Relación entre altura y diámetro:

$$
\frac{85}{165}: 0.51
$$

Relación entre altura del diámetro máximo y altura total:

$$
\frac{50}{85}: 0.59
$$

Esta última relación establece la diferencia con la forma IV de escudillas, además del tipo distinto de borde, en la forma IV directo, en la IX diferenciado abrupto por medio de un punto angular.

Es probable que la forma IX corresponda a las formas ilustradas por Latcham (1928: 112, fig. 6 y 114, fig. 47).

9. X. Vasijas compuestas, restringidas independientes, ovoide erecto-cilindro.

Son botellones de cuerpo ovoide y cuello cilíndrico o subcilíndrico, con las paredes ligeramente convexas. Número de vasijas: 38 (1.96\%) (Figura 8).

\subsection{Tamaño.}

90.0.0. Altura de la pieza: $261 \mathrm{~mm}$.

9.0.0.1. Altura del punto angular: $186 \mathrm{~mm}$.

9.0.0.2. Altura de las asas: $115 \mathrm{~mm}$.

9.0.1. Diámetro máximo: $183 \mathrm{~mm}$.

Relación entre la altura y el diámetro máximo:

$$
\frac{261}{183}: 1.4
$$

Relación entre la altura del cuello y la altura del cuerpo:

$$
\frac{75}{186}: 0.4
$$

Latcham (1928: 121, fig. 84) ilustra una vasija que se asemeja a esta forma. Estos botellones suelen presentar decoración en el cuello. En esos casos, han sido registrados en el subtipo Negro Pulido Decorado (Cuadro 1). 


\section{Otras formas (no representativas)}

9. XI. Vasos complejos, restringidos, biesferoide (cuerpo), hiperboloide (cuello).

Se caracterizan por presentar dos puntos de inflexión en el contorno. Llevan un asa en arco, doble adherida, vertical. La base es convexa-cóncava. Número de ejemplares: 4 (0.20\%) (ver Le Paige 1964: 201, láms. 105 y 224).

\subsection{Tamaño.}

9.0.0.0. Altura de la pieza: $194 \mathrm{~mm}$.

9.0.0.1. Altura del primer punto de inflexión: $96 \mathrm{~mm}$.

Altura riel segundo punto de inflexión: $156 \mathrm{~mm}$.

9.0.0.2. Altura del asa: $72 \mathrm{~mm}$.

9.0.1. Diámetro máximo: $173 \mathrm{~mm}$.

Relación entre altura y diámetro máximo:

$$
\frac{194}{113}: 1.7
$$

Relación entre altura del cuello y altura del cuerpo:

$$
\frac{38}{156}: 0.24
$$

9. XII. Vasijas compuestas, restringidas dependientes, bitronco-cónicas, con dos a cuatro asas dobles adheridas, en arco, posición vertical.

Número de ejemplares: 3 (0.15\%).

9. XIII. Vaso inflexionado, restringido, tronco-cónico, sección de hiperboloide.

Sin asa. Número de ejemplares: 1.

\section{Rasgos asociados a las diversas formas}

9.1. Espesor de las paredes: $4 \mathrm{~mm}$ a $7 \mathrm{~mm}$ en las proximidades de la base.

\subsection{Borde.}

9.4.0. Directo: Sin diferenciar del contorno del cuerpo y sin variación de espesor, se da en las formas I, II, III, IV (Figuras 1, 3, 4 y 5).

9.4.1. Diferenciado gradual, por medio de un punto de inflexión en dirección hacia afuera y hacia arriba. Se da en las formas V, VI, XI, XIII. En la forma $X$ se da en pocos casos y en el subtipo Negro Pulido Decorado, sólo en los botellones con decoración antropomorfa naturalista (Figura 9).

9.4.2. Diferenciado abrupto por medio de un punto angular, en dirección divergente. Además, el espesor de la pared disminuye en el borde. Es característico de las formas VII, VIII, IX, X, XII y botellones con decoración B (Figuras 6, $7,8,11)$.

\subsection{Labio.}

9.5.0/2. Recto o convexo: En las formas I, III, IV, V, VI, VIII, IX, XI.

9.5.1. Doble biselado: En las formas II, VII, X, XII, XIII.

\subsection{Base. ${ }^{3}$}

9.6.0/1. Biplana a plana-cóncava: La base biplana se asocia a las formas I y $\mathrm{V}$, jarros con un asa vertical. La base plana-cóncava se da en algunos casos de las formas III, IV, II y VIII. Total de casos: $551(28.5 \%)$.

9.6.2. Convexa-cóncava: Predomina en las formas VII, VI y IX. Total de casos: 1369 (70.3\%). En esta forma de base se da el modo.

9.6.3. En ángulo (base aguzada): Sólo se presenta en la forma X (Figura 8) y en Le Paige (1961: lám. 4; Núñez 1965: lám. IV, fig. 6). Total de casos: $9(0.46 \%)$. 


\subsection{Asas. Tres tipos}

9.7.0.0.0. Una o dos asas de doble inserción, doble adheridas (ver Munizaga 1963: lám. XII a y b).

9.7.1. Sección rectangular o circular (Figuras 1, 4, 8).

9.7.2.0.1. En arco, lisas.

9.7.3.0. Posición horizontal: 556 casos. Se da en las formas I, II, III y IV (Figuras 3, 4).

9.7.3.1. Posición vertical: 110 casos, de los cuales 101 casos se distribuyen entre las formas I y V (Figura 1).

9.7.0.0.1. Asas labio adheridas:

9.7.2.0.1. En arco, lisas.

\subsubsection{Posición horizontal: 27 casos.}

9.7.3.1. Posición vertical: 33 casos, asociadas en especial a la forma IV. Total de asas de doble inserción: 736 (47.4\%).

9.7.0.1.0. Dos asas-apéndices de inserción única, adheridas (Figura 6).

9.7.2.1.0/3. Macizas mamelonares con o sin perforación, en algunos casos-zoomorfas-, se trata de pequeñas asas no funcionales (ver Munizaga 1963: lám. XII c).

9.7.3.0. Posición horizontal de asas mamelonares: 117 casos. Asociadas a forma VII y IX.

9.7.3.1. Posición vertical de asas mamelonares: 475 casos. Se da en las mismas formas que en el caso anterior $\mathrm{y}$, además, en forma de apéndices otomorfos, en los botellones con decoración A y $\mathrm{B}$, en el cuello (Figuras 10 y 11) . Posición vertical de asas zoomorfas: 225 casos, en las formas u, VII, IV. Total de asas macizas de inserción única adheridas: 817 casos $(52.6 \%)$.

\section{Decoración.}

Dentro del tipo negro pulido distinguimos una variedad que hemos denominado Negro Pulido Decorado, porque a las características comunes de pasta, manufactura, acabado de superficies, color y forma, se agrega un nuevo rasgo: aparece una decoración al pastillaje o por extracción de materia sobre la superficie del cuello. El motivo decorativo puede ser realista con la representación de caras antropoformas o seguir una tendencia a la estilización hasta llegar a la pérdida de todo rasgo antropomorfo y su sustitución por un motivo geométrico de cinco a siete círculos, o en pocos casos cuatro, en dos hileras horizontales. A fin de marcar estas variaciones hemos diferenciado dos clases: la decoración A y B. (Cuadro 1).

Las vasijas tienen la forma de botellones con cuello alto muy semejantes a la forma $\mathrm{X}$ ya descrita, pero en la decoración $\mathrm{B}$ el cuello es más angosto, de paredes ligeramente convergentes y está perfectamente diferenciado por un ángulo en el contorno.

\section{Decoración A. Forma y rasgos asociados}

9. Forma.

Vasijas de contorno inflexionado (en escasa proporción) o compuesto, restringidas independientes, cuerpo ovoide erecto, cuello cilíndrico o hiperboloide. Se caracterizan por el borde evertido en forma gradual por medio de un punto de inflexión. Número de vasijas: 193 (10\%), (Figura 9) Le Paige (1964: 209, lám. 113, fig. 1), hace una comparación con una vasija rojo pulido con igual decoración.

\subsection{Tamaño.}

9.0.0.0. Altura de la pieza: $182 \mathrm{~mm}$.

9.0.0.1. Altura del punto de inflexión: $119 \mathrm{~mm}$.

9.0.0.3. Altura de los apéndices mamelonares otomorfos: $134 \mathrm{~mm}$.

9.0.1. Diámetro máximo: 142 mm.

Relación entre altura y diámetro máximo:

$$
\frac{182}{142}: 1.28
$$

Relación entre altura del cuello y altura del cuerpo:

$$
\frac{63}{119}: 0.52
$$


10. Decoración

10.1. Motivos decorativos. Cara antropoforma naturalista, aplicada sobre el cuello de la vasija en forma simétrica en ambas caras, por medio de pastillaje, con modelado de nariz y cejas mediante un reborde continuo, ojos salientes con una excavación central circular, boca y dientes, estos tres últimos ejecutados mediante extracción de materia. Todos estos rasgos han sido diseñados sobre un disco ovalado, en la mayoría de los casos, que hace la función del contorno del rostro. Las orejas, a ambos lados de la cara, tienen la forma de apéndices mamelonares perforados. Esta decoración se asemeja a la realizada sobre una vasija rojo pulido (ver Le Paige 1964: 209, lám. 113, fig. 1).

\section{Decoración B. Forma y rasgos asociados}

\section{Forma.}

Vasijas de contorno compuesto, restringidas independientes, cuerpo ovoide o subovoide, cuello cilíndrico, en algunos casos con las paredes ligeramente convexas. El borde se diferencia en forma neta por medio de un punto angular. Número de vasijas: 137 (7.11\%). (Figuras 10 y 11; Le Paige 1964: 203, lám. 106).

\subsection{Tamaño.}

9.0.0.0. Altura de la pieza: $188 \mathrm{~mm}$.

9.0.0.1. Altura del punto angular: $136 \mathrm{~mm}$.

9.0.0.3. Altura de los apéndices mamelonares otomorfos: $137 \mathrm{~mm}$.

9.0.1. Diámetro máximo: 144 mm.

Relación entre altura del cuelo y altura del cuerpo:

$$
\frac{52}{136}: 0.38
$$

Relación entre altura y diámetro máximo: 188.

$$
\frac{188}{144}: 1.3
$$

\section{Decoración.}

10.1. Motivos decorativos: Transición. Se produce la pérdida de algunos de los rasgos del rostro.
La boca, las cejas y la nariz se unen a la línea del óvalo, los ojos no se aplican ya al pastillaje sino simplemente se hace un hoyo por extracción de materia (Figura 10; Orellana 1962a). Esquematización total. La decoración queda reducida a cinco o siete círculos, obtenidos mediante remoción de materia. Generalmente, el cuello es un cilindro perfecto, con un predominio acentuado de la altura sobre el diámetro transverso, lo que le confiere una figura muy estilizada (Figura 11; Orellana 1963: lám. I; Le Paige 1961: lám. 1). Creemos que estas variaciones decorativas se deben a diferencias temporales, probablemente la decoración A sea la más antigua.

\section{Observaciones}

En conjunto, el tipo de base que predomina es la convexa-cóncava. La base biplana o plana-cóncava sólo alcanza un porcentaje elevado en aquellos sitios donde se da la forma de jarros I y V. Los vasos de forma II y III presentan los dos tipos de base, aunque con tendencia a un predominio de la base convexa-cóncava. En la forma VII se da esta última prácticamente en todos los casos, al igual que en la forma IV y IX. Estas dos formas corresponden al tipo de vasija denominada corrientemente "puco" o "escudilla".

Otros rasgos que cambian según las formas es el tipo de asa, que varía desde el asa doble adherida lisa de la forma I, donde responde al carácter funcional, hasta las asas-apéndices de la forma VII, muy pequeñas, en forma de mamelones macizos, evidentemente no funcionales.

Se observa también una variación en el tipo de borde de las vasijas, desde el borde directo siempre asociado a la forma I, III y IV hasta el borde diferenciado abrupto de la forma VII y IX.

Del análisis del Cuadro 1 se desprende que la forma más popular es la III (vaso troncocónico), donde cae el modo con 382 casos, siguiéndole en orden decreciente la forma VII y la IV.

Circunscribiéndonos a las dos formas más populares, encontramos que el mayor número de casos de cada una de estas formas se da en distintos sectores de un mismo sitio (Solor 3). El modo de la forma III se da en Solor 3, Parte Occidental del Túmulo Norte, siguiéndole por el número de casos, Quitor 5. 


\begin{tabular}{|c|c|c|c|c|c|c|c|c|c|c|c|c|c|c|c|c|c|c|c|}
\hline$\gamma^{\text {Sitios }}$ & 㣽. & 㣽. & 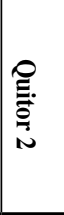 & 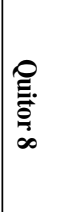 & 导 & 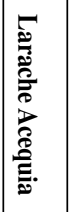 & 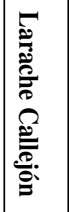 & 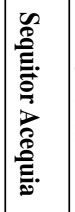 & 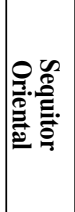 & 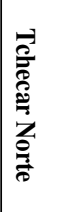 & 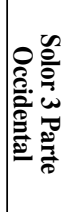 & 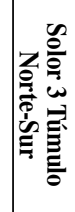 & $\frac{\beta}{8}$ & 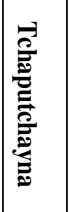 & 兽 & 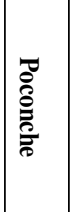 & 䇂 & $\overrightarrow{\overrightarrow{0}}$ & 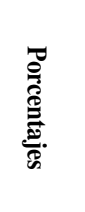 \\
\hline I & 22 & 11 & 22 & 7 & 15 & 8 & 4 & 71 & 5 & 2 & 25 & & 3 & & 2 & & & 199 & 10.31 \\
\hline II & 18 & 51 & 20 & 2 & 2 & 4 & 3 & 59 & 2 & & 8 & & & 3 & 1 & & & 173 & 8.96 \\
\hline III & 67 & 29 & 20 & 12 & 53 & 29 & 5 & 46 & 11 & 2 & 87 & 8 & 4 & & 4 & & 5 & 382 & 19.80 \\
\hline IV & 33 & 33 & 11 & 1 & 12 & & 7 & 65 & 22 & 3 & 16 & 34 & 5 & 1 & & 2 & 1 & 246 & 12.75 \\
\hline $\mathrm{V}$ & 9 & & & 7 & 9 & & & 3 & 2 & & 2 & & & & & & & 32 & 1.65 \\
\hline VI & 7 & 1 & & & 4 & 3 & & & & & & & & & & & & 15 & 0.77 \\
\hline VII & 36 & 60 & 21 & & 10 & 9 & & 54 & 16 & 2 & 2 & 99 & 5 & 12 & 1 & & & 327 & 16.95 \\
\hline VIII & 11 & 3 & 1 & & 7 & & 8 & 4 & & 3 & 1 & 1 & & 2 & & & & 41 & 2.12 \\
\hline IX & 19 & 30 & 10 & & 3 & 8 & & 21 & 10 & 1 & & 31 & & & 1 & & & 134 & 6.94 \\
\hline$X$ & & 13 & 5 & 3 & & 4 & 5 & & 4 & & & 3 & & & 1 & & & 38 & 1.96 \\
\hline XI & 1 & & & & 1 & & & 1 & 1 & & & & & & & & & 4 & 0.20 \\
\hline XII & 1 & & & & & & 1 & 1 & & & & & & & & & & 3 & 0.15 \\
\hline XIII & & & & & & & & & 1 & & & & & & & & & 1 & 0.05 \\
\hline Total parcial & 226 & 231 & 110 & 32 & 116 & 65 & 33 & 325 & 74 & 13 & 141 & 176 & 17 & 18 & 10 & 2 & 6 & 1595 & 82.61 \\
\hline Decoración A & 25 & 32 & 32 & 11 & 3 & 5 & 9 & 65 & 4 & & 5 & 2 & & & & & & 193 & 10.00 \\
\hline Decoración B & 16 & 52 & 8 & 1 & 3 & 2 & 3 & 32 & 11 & & 3 & 6 & & & & & & 137 & 7.11 \\
\hline Total parcial & 41 & 84 & 40 & 12 & 6 & 7 & 12 & 97 & 15 & & 8 & 8 & & & & & & 330 & 17.11 \\
\hline Total excepción & & & & & & & 1 & 3 & & & & & & & & & & 4 & 0.21 \\
\hline Total & 267 & 315 & 150 & 44 & 122 & 72 & 46 & 425 & 89 & 13 & 149 & 184 & 17 & 18 & 10 & 2 & 6 & 1929 & $\begin{array}{c}\text { Ajuste } \\
0.07\end{array}$ \\
\hline Porcentajes & 13.84 & 16.32 & 7.77 & 2.28 & 6.32 & 3.73 & 2.38 & 22.03 & 4.61 & 0.67 & 7.72 & 9.53 & 0.88 & 0.93 & 0.51 & 0.10 & 0.31 & $\begin{array}{c}\text { Ajuste } \\
\mathbf{0 . 0 7}\end{array}$ & 100.0 \\
\hline
\end{tabular}

Cuadro 1. Frecuencias del tipo Negro Pulido según sus formas, por sitios (San Pedro de Atacama, noviembre de 1964).

El modo de la forma VII cae en Solor 3, Túmulo Norte-Sur. Le sigue Quitor 6 en orden decreciente. Consideramos que es importante la inversión de las curvas de frecuencias de las formas del negro pulido en los sitios Solor 3, Parte Occidental, con respecto al Túmulo Norte-Sur y Quitor 5 con respecto a Quitor 6 (Cuadro 1). La aplicación de la prueba de hipótesis $\left(x^{2}\right)$ nos corroboró la idea de que estas diferencias no se debían al azar sino que, por el contrario, eran altamente significativas. Aplicamos luego, como otro medio de control, el método gráfico de seriación de Ford (1962). Utilizamos los distintos porcentajes de las formas del negro pulido tomando como unidad cada sitio. Al formar los husos, los de las formas III y VII se alejaron hacia los extremos opuestos, quedando en un extremo el sitio Solor 3, Parte Occidental, en relación con la forma III y, en el opuesto, Solor 3, Túmulo Norte-Sur, en conexión con la forma VII. Este resultado es congruente con el anterior.
Cabe destacar, además, que en los lugares con predominio de forma III, se da también un porcentaje elevado de I y una preponderancia de la decoración A sobre la B. También, a veces, una proporción considerable de IV.

Donde predomina la forma VII ocurre un porcentaje relativamente elevado de las escudillas de forma IX, a veces también un aumento de los vasos II (los tres con borde diferenciado abrupto por medio de un ángulo, en contraste con las formas antes mencionadas). Se da, además, una preponderancia de la decoración $B$ sobre la A, en especial en Quitor 6.

Se puede agregar otro hecho significativo. En Solor 3, Parte Occidental, y en Quitor 5 (Parte Occidental), aparece el tipo San Pedro Rojo Pulido, mientras que en Solor 3, Túmulo Norte-Sur y en Quitor 6, su aparición es prácticamente nula. 
Si bien no trataremos aquí las asociaciones de tumbas, deseamos destacar que la forma de negro pulido que se asocia en la mayoría de los casos a la alfarería roja pulida es la forma III (tipo de asociación 4, Tarragó 1968: 130), mientras que la forma VII, en general, no se asocia y lo hace en cambio con tabletas de madera con grabados típicos de Tiahuanaco y cerámica Tiahuanaco o de esa influencia (tipo de asociación 6, Tarragó 1968: 131). En síntesis, de acuerdo con los resultados de la seriación pensamos que la tradición de cerámica monocroma negra bruñida comienza en tiempos pretiahuanacos, fase II y fase III cuando se inicia la penetración de esa cultura, alcanza su máximo desarrollo en la fase IV, disminuye notablemente su producción en la fase V y hacia 900 DC ha desaparecido (Tarragó 1968: 140-141). En el cuadro resumen de las secuencias cerámicas que presentó el padre Le Paige en el Congreso Internacional de Arqueología de San Pedro de Atacama, ya se plantea la subdivisión en fases dentro del intervalo de desarrollo de la alfarería negra pulida (1963: 196-197).

En relación con lo anterior, es necesario señalar que dentro de la cerámica negra pulida se dan ejemplares con superficies negras pulidas pero de pasta rosada que Le Paige llama cerámica negra "casi pulida". Aumenta en estas piezas el espesor de las paredes con respecto a las vasijas típicas y disminuye la calidad de la pasta. Esto ocurre en relación con la forma VI (Le Paige 1964: lám. 134, fig. 1) y una forma subcilíndrica distinta de la forma I. Disminuye la altura del vaso con respecto al diámetro máximo y los bordes se abren ligeramente hacia afuera. Tienen base plana y un asa doble adherida en arco, posición vertical, de mayor tamaño que en la forma I. Según Le Paige, este grupo aparece en distintos sectores de los cementerios de Quitor 5 y 6, mientras que el negro pulido típico se da en la Parte Oriental y Central de Quitor 5 y en la Parte Meridional de Quitor 6, el negro "casi pulido" aparece en la Parte Occidental de Quitor 5 y en la Parte Septentrional de Quitor 6 (Le Paige 1964: 60 y 67). Nosotros no hemos podido indagar más al respecto, puesto que trabajamos con piezas enteras. Es posible que futuros estudios permitan un desdoblamiento del tipo.

\section{Alfarería roja pulida}

Se trata de vasijas rojas pulidas, cocidas en atmósfera oxidante, que se particularizan por la uniformidad de forma y tamaño; cántaros esferoides con cuello evertido, base plana, sin asas o con mamelones pequeños no funcionales. Sigue en popularidad al tipo Negro Pulido, pero con una proporción de apariciones siete veces menor.

0. Nombre: San Pedro de Atacama Rojo Pulido.

1. Otros nombres: "Cerámica colorada pulida globular" (Le Paige 1963: 13), "San Pedro de Atacama rojo pulido globular" (Le Paige 1964: 53), "San Pedro Rojo Pulido" (Orellana 1963a; Núñez 1965).

Procedencia: San Pedro de Atacama (Cuadro 2). Lugares: Larache Acequia, Sequitor Alambrado Acequia, Solor 3 Parte Occidental del Túmulo Norte, Quitor 5 Parte Oriental, Quitor 7, Quitor 8 Parte Central, Quitor 9. ${ }^{4}$

3. Sitio tipo: San Pedro de Atacama.

4. Número de ejemplares de la muestra: 278 .

5. Pasta:

\subsection{Antiplástico:}

5.1.0. Composición. Predominan las plagioclasas de composición andesina, maciadas y zonadas; cuarzo límpido, hornblenda verde y gránulos de óxido de hierro. Se observan clastos de material arcilloso vitrificado. La forma de los clastos es redondeada a subredondeada (ver Apéndice, muestra 3).

5.1.1.0.1. Tamaño: No uniforme. De $2.5 \mathrm{~mm}$ a $0.1 \mathrm{~mm}$.

5.1.1.1.2. Mediano, como término medio.

5.1.2.0. Distribución: Regular.

5.1.3.1. Densidad: Denso.

\subsection{Textura:}

5.2.0.0.1. No uniforme.

5.2.0.1.2. Mediana.

5.2.2.0. Regular.

4 Según comunicación del padre Le Paige, también aparece en Quitor 2. 


\subsection{Densa.}

\subsubsection{1/2. Semicompacta a porosa.}

\subsection{Fractura:}

\subsubsection{Irregular.}

5.4. Color: Centro del núcleo y partes adyacentes a las superficies, rojizo a castaño.

6. Manufactura: Enrollamiento.

7. Superficie:

7.0. Color: (exterior) rojizo, (interior) castaño claro.

7.1. Dureza: 4 a 5 (Escala de Mohs).

\subsection{Regularidad:}

\subsubsection{Regular en la superficie externa.}

\subsubsection{Irregular en la superficie interna.}

7.3. Tratamiento: Pulimento exterior; interior: pulimento en parte del cuello, el resto alisamiento. Pulimento con guijarro que dejan en muchas piezas las estrías de pulimento en sentido vertical.

7.4. Baños: Se observa la aplicación de un engobe rojo en forma de una película fina sobre la superficie externa y en la interna en la parte del borde, que tapa los poros de la pasta y le da consistencia a la superficie. Luego se ha realizado el pulimento.

7.5. Defectos: Manchas negruzcas por defectos 9.4. Borde: de cocción. Es característico del tipo.

8. Cocción:

\subsubsection{Oxidante.}

\subsubsection{Cocida.}

\subsubsection{Irregular.}

\section{Forma:}

9.2.3. Vasijas inflexionadas de boca restringida, cuerpo esferoide o subesferoide, cuello hiperboloide. Le Paige la define como "roja pulida globular" (1963a: 12); Orellana (1963a) como "cántaros de cuerpo globular, de base plana, con un cuello cuyas paredes terminan en un borde abierto" (Figura 12).

\subsection{Tamaño: Medidas promedio.}

9.0.0.0. Altura de la pieza: $275 \mathrm{~mm}$.

9.0.0.1. Altura del punto de inflexión: $202 \mathrm{~mm}$. 9.0.0.2/3. Altura de las asas-apéndices: $220 \mathrm{~mm}$.

9.0.1. Diámetro máximo: $222 \mathrm{~mm}$. Diámetro de la boca: $73 \mathrm{~mm}$.

Relación entre altura y diámetro máximo:

$$
\frac{275}{222}: 1.23
$$

Relación entre altura del cuello y altura del cuerpo:

$$
\frac{73}{202}: 0.36
$$

9.1. Espesor de las paredes: 6 a $9 \mathrm{~mm}$ del borde a la base.

\subsection{Borde:}

9.4.1. Evertido: Diferenciado gradual por medio de un punto de inflexión.

\subsection{Labio:}

\subsubsection{Convexo.}

9.6. Base: (Cuadro 2).

9.6.1. Plana-cóncava: 254 casos (modo).

9.6.2. Convexa: Sin diferenciarse del contorno del cuerpo: 18 casos.

9.6.3. Angular: Cónica, siguiendo el contorno ovoide invertido del cuerpo: 3 casos.

9.6.4. Cóncava-convexa: 3 casos.

9.7. Asas: (Cuadro 2).

9.7.0.0.0. De doble inserción doble adheridas: 3 casos.

9.7.0. De inserción única adherida: 134 casos (modo). 
9.7.1. Por su sección subrectangular, semicircular, respectivamente.

9.7.2.0. En arco lisas: 3 casos (en relación con 9.7.0.0.).

9.7.2.1.0. Macizas mamelonares: 134 casos (en relación 9.7.0). Constituyen las asas características del tipo. Orellana (1963a) señala, en este sentido, que en muchos casos aparecen en el cuello "asitas verticales de forma protuberencial y horadadas".

\subsubsection{Por su posición: verticales.}

10. Decoración: (Excepcional).

10.0. Técnicas: Pastillaje y modelamiento.

10.1. Motivos: Sobre la superficie del cuello se ha aplicado una decoración en forma de cara antropomorfa semejante a la decoración A del tipo San Pedro Negro Pulido (Le Paige 1964: 209, lám. 113, fig. 1; Núñez 1965: lám. III, fig. 2).

\section{Observaciones}

Hasta el momento en que se llevó a cabo este trabajo no fue posible comprobar la postulación de una posición cronológica anterior del tipo Rojo Pulido, con respecto al Negro Pulido. El sitio de Larache Acequia, donde esto se confirmaría, ha sufrido el efecto de aluviones como el padre Le Paige lo señala
(1964: 63). En cambio, por su comportamiento en las tumbas bien registradas, es indudable su asociación al Negro Pulido de forma III y I, que creemos se encuentran entre las formas más tempranas de este último tipo. Aparentemente, el Rojo Pulido se relacionaría con las primeras fases del Negro Pulido (tipo de asociación 1, 2, 3 y 4, Tarragó 1968: 129-130).

La asociación de cerámica roja pulida en tres tumbas a tabletas planiformes con motivos tiahuanaco sugiere que esa tradición alfarera puede haber llegado a la época de influencia tiahuanaco. Pero también en este caso es necesario un mayor acopio de datos diagnósticos que corroboren lo observado y constituyan un escalón firme en las secuencias.

Hemos separado de este tipo como un grupo distinto, varios vasos, menos de una docena, que se reparten entre Sequitor Alambrado Acequia y Quitor 8. Se trata de una alfarería rojo-naranja bruñida, de pasta delgada y fina. Se diferencian de los cántaros San Pedro Rojo Pulido, típicos por su forma (jarros de contorno simple, boca no restringida, cilíndricos), por la calidad de su pasta y manufactura, el escaso espesor de sus paredes y una técnica más cuidadosa de acabado de superficie que les ha conferido un aspecto lustroso. Cuando se asocia un asa en arco vertical, reproducen en rojo la forma I del tipo Negro Pulido. En otros casos, presentan dos mamelones macizos verticales cerca del borde. En Quitor 8, tumba 3174-75, se encontraron ejemplares de estos vasos junto con vasijas negras pulidas de forma I y III, que creemos predominaron al comienzo de

\begin{tabular}{|c|c|c|c|c|c|c|c|c|c|c|c|}
\hline \multirow[b]{3}{*}{ Sitios } & \multicolumn{11}{|c|}{ Bases y asas } \\
\hline & \multicolumn{3}{|c|}{ Convexa-cóncava } & \multirow{2}{*}{$\begin{array}{l}\text { Angular } \\
\text { Sin asas }\end{array}$} & \multicolumn{3}{|c|}{ Plana-cóncava } & \multicolumn{2}{|c|}{ Conv.-Conv. } & \multirow[b]{2}{*}{ Total } & \multirow[b]{2}{*}{ Porc. } \\
\hline & Sin asas & Mamelón & $\begin{array}{c}\text { Mamelón } \\
\text { Perf. }\end{array}$ & & Sin asas & Mamelón & $\begin{array}{c}\text { Mamelón } \\
\text { Perf. }\end{array}$ & Asa & Mamelón & & \\
\hline $\begin{array}{l}\text { Larache } \\
\text { Acequia }\end{array}$ & - & - & - & - & 5 & 9 & 1 & - & - & 15 & 5.4 \\
\hline $\begin{array}{l}\text { Sequitor } \\
\text { A1. Acequia }\end{array}$ & 6 & - & 8 & 2 & 93 & 67 & 19 & 3 & 2 & 200 & 71.9 \\
\hline $\begin{array}{l}\text { Solor } 3 \\
\text { P. Occidental }\end{array}$ & - & - & - & - & 14 & 6 & 1 & - & - & 21 & 7.6 \\
\hline Quitor 8 & - & 3 & - & - & 13 & 16 & - & - & 1 & 33 & 11.9 \\
\hline Quitor 9 & - & - & - & 1 & 1 & - & - & - & - & 2 & 0.7 \\
\hline Quitor 5 & - & 1 & - & - & 4 & - & - & - & - & 5 & 1.8 \\
\hline Quitor 7 & - & - & - & - & 2 & - & - & - & - & 2 & 0.7 \\
\hline Total & 6 & 4 & 8 & 3 & 132 & 98 & 21 & 3 & 3 & 278 & \\
\hline Porcentaje & 2.1 & 1.4 & 2.9 & 1.1 & 47.5 & 35.2 & 7.6 & 1.1 & 1.1 & & $100 \%$ \\
\hline
\end{tabular}

Cuadro 2. Distribución del tipo Rojo Pulido según tipo de base y asas por sitios (San Pedro de Atacama, noviembre de 1964). 
la tradición alfarera del tipo Negro Pulido (tipo de asociación 3 y 4, Tarragó 1968: 130).

Otro hecho que nos llamó la atención al analizar el tipo Rojo Pulido fue encontrar 29 piezas con un engobe rojo sin pulir que se desprendía fácilmente con el roce. Es posible que se trate de un engobe postcocción. En relación con el empleo de esta técnica, descubrimos luego dos vasijas alisadas de pasta y superficies grises que estaban cubiertas por una gruesa capa de engobe rojo que se separaba a modo de cáscara por carecer de afinidad con la pasta (Figura 13).

Los demás rasgos de las vasijas rojas alisadas son semejantes a los cántaros pulidos, excepto en cuanto a la dureza de las superficies que es aproximadamente de 3.5 por carecer de pulimento. Predominan los apéndices mamelonares y la base plana-cóncava.

Procedencia: 11 ejemplares de Sequitor Alambrado Acequia; cinco de Solor 3 Parte Occidental; ocho de Quitor 8; uno de Quitor 9; cuatro de Quitor 5.

La ubicación de este grupo como un tipo distinto del Rojo Pulido dependerá del hecho que sea un tratamiento intencional de las superficies. Posiblemente, representen las formas más tardías de la tradición de cerámica monocroma roja. El padre Le Paige, al hablar de la posición temporal de Quitor 5, destaca la presencia de "cántaros de greda tipo San Pedro de Atacama rojo pulido, de los cuales ya ha desaparecido la brillantez y en los que la greda es menos resistente" (1964: 63).

\section{Alfarería negra grabada}

Designa un grupo de vasijas de pasta semejante al Negro Pulido, pero con el agregado de una decoración geométrica grabada en la superficie externa de escudillas hemisféricas o subcónicas. Se singularizan por la ejecución descuidada del diseño y por el bajo porcentaje en comparación con los tipos Negro y Rojo Pulido.

0. Nombre: San Pedro de Atacama Negro Grabado.

1. Otros nombres: "Cerámica negra incisa" (Le Paige 1963: 12); "San Pedro de Atacama negro pulido inciso" (1964: 53); "San Pedro Inciso" (Munizaga 1963), "San Pedro Inciso Negro Pulido" (Orellana 1963b: 34). Hemos reemplazado inciso por grabado debido a que se ha aplicado la "técnica decorativa realizada con un instrumento filoso cuando la pasta de la pieza cerámica está dura, antes o después de la cocción, deja líneas ásperas y de bordes irregulares" (acordado por convención, Córdoba, 1964). Reservamos el término inciso para la decoración ejecutada en pasta blanda que ocasiona un desplazamiento de materia.

2. Procedencia: San Pedro de Atacama (Cuadro 3).

Lugares: Coyo, Tchaputchayna, Larache 7. Callejón, Quitor 2, 5, 6, 8, Solor 3 Túmulo Norte-Sur, Sequitor Alambrado Oriental, Tchecar Sur.

3. Sitio tipo: San Pedro de Atacama.

4. Número de ejemplares de la muestra: 40.

5. Pasta.

\subsection{Antiplástico:}

5.1.0. Composición: Similar al tipo negro pulido, fragmentos de cuarzo, plagioclasas, ortosa, hornblenda, biotita y gránulos de óxido de hierro.

\subsection{Tamaño: No uniforme.}

5.1.1.1.1/2. Fino a mediano: 1.5 a $0.1 \mathrm{~mm}$.

5.1.2.0. Distribución: Regular.

5.1.3.1. Densidad: Denso.

\subsection{Textura:}

5.2.0.0.1. No uniforme.

5.2.0.1.1/2. Fina a mediana.

5.20.2.0. Regular.

5.2.0.3.1. Densa.

5.2.1.1. Laminar.

5.3. Fracturas: Irregular.

5.4. Color: Núcleo y partes adyacentes a las superficies, pardusco a gris. 
6. Manufactura: Probablemente enrollamiento. Munizaga señala que varios fragmentos analizados, por el tipo de fractura, muestran evidencias de coiling (1963: 104).

7. Superficie:

7.0. Color: interna y externa, negra a gris.

7.1. Dureza: 4 (Escala de Mohs).

7.2.0. Regularidad: Regular.

7.3. Tratamiento: Pulimento en superficie interna y externa realizado con un instrumento menos regular que en el caso del Negro Pulido. Se observan anchas estrías horizontales.

7.4. Baños: El análisis de una muestra de Negro Grabado resultó similar a las muestras del Negro Pulido con la presencia de láminas de hematita, variedad especularita, en las superficies (ver Apéndice).

7.5. Defectos: Manchas por cocción irregular.

8. Cocción.

8.0.0. Reductora.

8.1.2. Cocida.

\subsubsection{Irregular.}

9. Forma: Se presentan las siguientes formas (Cuadro 3):

9.2. A. Escudillas simples, no restringidas, sección de esfera, principalmente hemisféricas, con sólo puntos terminales o puntos terminales y un punto de tangencia vertical (Munizaga 1963: lám. IV, figs. 5 y 6; Le Paige 1963a: láms. III, IV, V, VI, VII; 1964: láms. 103, 109, 133) (Figura 14).

B. Vasos simples no restringidos, subtronco-cónicos invertidos, con sólo puntos terminales (Le Paige 1964: lám. 134, fig. 2).

C. Vaso simple, restringido, cuerpo ovoide con una insinuación de inflexión que determina un borde recto. Transición a forma $\mathrm{D}$.
9.2/3. D. Botellón de contorno inflexionado, boca restringida, cuerpo ovoide, cuello hiperboloide (Munizaga 1963: lám. V, fig. 3).

E. Vaso complejo, restringido, bitronco-cónico, borde evertido.

Se registró, además, una vasija asimétrica, ornitomorfa, que se aleja del tipo tanto por su forma como por la técnica usada en la decoración, incisiones en pasta blanda muy bien ejecutadas, los surcos rellenos de una sustancia blanquecina (Munizaga 1963: lám. V. fig. 1).

9.0. Tamaño: Forma A.

9.0.0.0. Altura de la pieza: $85 \mathrm{~mm}$.

9.0.1. Diámetro máximo: $133 \mathrm{~mm}$.

Relación entre altura y diámetro máximo:

$\frac{85}{133}: 0.63$

9.0. Tamaño: Forma B.

9.0.0.0. Altura de la pieza: $103 \mathrm{~mm}$.

9.0.1. Diámetro máximo: $135 \mathrm{~mm}$.

Relación entre altura y diámetro máximo (coincide con la boca):

$$
\frac{103}{135}: 0.76
$$

9.1. Espesor de las paredes: 4 a $7 \mathrm{~mm}$ desde el borde a la base.

\subsection{Borde:}

9.4.0. Directo: Forma B, en varios ejemplares con un ligero engrosamiento.

9.4.1. Diferenciado gradual evertido: Forma A, C, D, E.

9.5.2. Labio: Convexo.

9.6. Base: (Cuadro 3).

9.6.1. Plana-cóncava: 33 casos.

9.6.2. Convexa-cóncava: 7 casos. 
10. Decoración:

10.0. Técnica: Grabamiento en pasta dura y seca que determina un desprendimiento de partículas e irregularidades que dan como resultado un diseño muy descuidado. Sólo dos o tres ejemplares presentan incisiones en pasta más blanda como en el caso de la forma $\mathrm{D}$.

10.1. Motivos: Geométricos rectilíneos y curvilíneos, con predominio de los primeros. Líneas paralelas verticales, reticulados formando triángulos o rectángulos, rombos o espirales rellenas con puntos, "juego de cola" (sensu Le Paige). Este último consiste en una figura formada por dos trapecios o rectángulos adosados que sugieren el cuerpo estilizado de un camélido. La "cola", una o varias, son líneas que nacen en el cuerpo y terminan en dos círculos concéntricos, muy irregulares debido a la técnica de grabado (Le Paige 1963: lám. V). Este motivo decorativo se asocia a la forma A mientras que las volutas a la forma B. Muchos ejemplares presentan las líneas grabadas rellenas con una sustancia blanca.

\section{Observaciones}

En relación con la tradición de alfarería grabada cocida en atmósfera reductora se halla una colección de fragmentos de vasos de tamaño grande, con procedencia en su mayor parte de Tchecar. No se ha recuperado ninguno completo pero es posible determinar su forma general y los motivos decorativos. Son de forma cilíndrica, con borde evertido marcado por un punto de inflexión, base biplana, asas doble adheridas de sección subrectangular en arco, posición vertical. Los motivos decorativos, ejecutados mediante la técnica de grabamiento, son congruentes con los descritos para el tipo. Consisten en series alternantes de rombos concéntricos y dameros rellenos con puntos; serie de triángulos rellenos con líneas paralelas y volutas. En la superficie externa del borde se observa una banda compuesta por zigzag horizontales, al igual que ocurre en los pucos típicos (formas A y B) del Negro Grabado.

Del análisis del Cuadro 3 se deduce que la forma por excelencia es la $\mathrm{A}$, de base plana-cóncava. $\mathrm{La}$ decoración se caracteriza por el grabado tan irregular y por el motivo "juego de cola" (Le Paige 1963a: figs. 1 a 10).

Por su comportamiento en las tumbas, el Negro Grabado se da en los tipos de asociación 7, 8 y 9, es decir, su aparición como alfarería funeraria se da en la fase IV, en el grupo de tumbas con San Pedro Negro Pulido, Negro y Rojo Grabado y Tiahuanaco puro y en la fase $\mathrm{V}$, en el grupo de tumbas con

\begin{tabular}{|c|c|c|c|c|c|c|c|c|c|}
\hline \multirow{3}{*}{ Sitios } & \multicolumn{7}{|c|}{ Formas y bases } & \multirow{3}{*}{ Total } & \multirow{3}{*}{ Porc. } \\
\hline & \multicolumn{2}{|c|}{$\mathbf{A}$} & \multicolumn{2}{|c|}{ B } & \multirow{2}{*}{$\begin{array}{c}\text { C } \\
\begin{array}{c}\text { Convexa- } \\
\text { cóncava }\end{array}\end{array}$} & \multirow{2}{*}{$\begin{array}{c}\text { D } \\
\begin{array}{c}\text { Plana- } \\
\text { cóncava }\end{array}\end{array}$} & \multirow{2}{*}{$\begin{array}{c}\text { E } \\
\begin{array}{c}\text { Plana- } \\
\text { cóncava }\end{array}\end{array}$} & & \\
\hline & $\begin{array}{l}\text { Plana- } \\
\text { cóncava }\end{array}$ & $\begin{array}{l}\text { Convexa- } \\
\text { cóncava }\end{array}$ & $\begin{array}{l}\text { Plana- } \\
\text { cóncava }\end{array}$ & $\begin{array}{c}\text { Convexa- } \\
\text { cóncava }\end{array}$ & & & & & \\
\hline Coyo & 2 & & & 1 & & & & 3 & 7.5 \\
\hline Tchaputchayna & 3 & & & & & & & 3 & 7.5 \\
\hline Larache Callejón & 4 & & & & & & & 4 & 10.0 \\
\hline Quitor 8 & 1 & & & & & & & 1 & 2.5 \\
\hline Quitor 5 & 3 & 1 & 2 & 1 & 1 & & 1 & 9 & 22.5 \\
\hline Quitor 6 & 1 & & & 1 & & & & 2 & 5.0 \\
\hline Quitor 2 & 1 & & 1 & & & & & 2 & 5.0 \\
\hline $\begin{array}{l}\text { Solor } 3 \text { Túmulo } \\
\text { Norte-Sur }\end{array}$ & 5 & 1 & 3 & & & 1 & & 10 & 25.0 \\
\hline Sequitor Acequia & 2 & 1 & & & & & & 3 & 7.5 \\
\hline Tchecar Sur & 2 & & 1 & & & & & 3 & 7.5 \\
\hline Total & 24 & 3 & 7 & 3 & 1 & 1 & 1 & 40 & \\
\hline Porcentaje & 60.0 & 7.5 & 17.5 & 7.5 & 2.5 & 2.5 & 2.5 & & 100.0 \\
\hline
\end{tabular}

Cuadro 3. Frecuencias del tipo negro grabado según sus formas y bases por sitios. No se incluyó la vasija ornitomorfa de Solor 3 Túmulo Norte-Sur, tumba 937 (San Pedro de Atacama, noviembre de 1964). 
San Pedro Negro Pulido en disminución, Negro y Rojo Grabado, Gris Pulido Grueso y Tiahuanaco Transformado. Es posible que la alfarería grabada perdure un poco más que la tradición negra pulida, como serían los casos de asociación con el Gris Pulido Grueso (Tarragó 1968: 132, 140-141).

\section{Alfarería roja grabada}

Comprende un grupo de escudillas de boca no restringida y superficies rojas pulidas, con una decoración externa de líneas grabadas que determinan un diseño tosco. El porcentaje de apariciones es aún inferior al Negro Grabado. Sin duda, ambos tipos se relacionan con una misma tradición alfarera cuyas raíces se encuentran probablemente fuera del área de San Pedro de Atacama.

0. Nombre: San Pedro de Atacama Rojo Grabado.

1. Otros nombres: "Cerámica roja incisa" (Le Paige 1963a: 12), "San Pedro de Atacama rojo pulido inciso" (1964: 53); "San Pedro Inciso Rojo Pulido" (Orellana 1963b: 34); "San Pedro Inciso" (Munizaga 1963). Se reemplazó el término inciso por grabado por el mismo motivo que en el tipo Negro Grabado.

2. Procedencia: San Pedro de Atacama.

Lugares: Solor 3 Túmulo Norte-Sur, Quitor 5, 6, Sequitor Oriental, Larache Callejón (Cuadro 4).

3. Sitio tipo: San Pedro de Atacama.

4. Número de ejemplares de la muestra: 14.

5. Pasta:

\subsection{Antiplástico.}

5.1.0. Composición: Cuarzo, plagioclasas.

5.1.1.0.1. Tamaño: No uniforme.

5.1.1.1.1/2. Fino a mediano.

5.1.2.0. Distribución: Regular.

5.1.3.1. Densidad: Denso.
5.2. Textura:

5.2.0.0.1. No uniforme.

5.2.0.1.1/2. Fina a mediana.

5.2.0.2.0. Regular.

5.2.0.3.1. Densa.

5.2.1.1. Laminar. Tendencia a desprenderse en capas.

5.3. Fractura: Irregular.

5.4. Color: Centro del núcleo gris pardo, partes adyacentes a las superficies rojas o pardas.

6. Manufactura: Probable enrollamiento.

7. Superficie:

7.0. Color: Rojizo interior y exterior.

7.1. Dureza: 4 (Escala de Mohs).

7.2. Regularidad: Regular en ambas superficies.

7.3. Tratamiento: Alisamiento, pulimento.

7.4. Baños: Capa de pintura o engobe rojo en toda la superficie externa y en la cara interna del borde, o en ambas superficies.

7.5. Defectos: Manchas parduscas y grisáceas por defectos de cocción.

8. Cocción:

8.0.1. Oxidante.

\subsubsection{Cocida.}

\subsubsection{Irregular.}

9. Forma: Se registraron las siguientes formas de escudillas o pucos.

9.2.1. Vasijas simples, no restringidas, troncocónicas o subcónicas invertidas (Figura 17; Munizaga 1963: lám. IV, figs. 3 y 4). 
2. Vasijas simples, no restringidas, sección de esfera, en especial, hemisféricas, borde evertido.

3. Escudillas de contorno compuesto, con un ángulo a mitad del cuerpo que marca dos secciones de conos, la boca no restringida. (Figuras 15 y 16; Munizaga 1963: lám. IV, fig. 2).

\subsection{Tamaño: Forma 1.}

9.0.0.0. Altura de la pieza: $97 \mathrm{~mm}$.

9.0.1. Diámetro máximo, que coincide con la abertura de la boca: $124 \mathrm{~mm}$.

Relación entre altura y diámetro:

$$
\frac{97}{124}: 0.78
$$

\subsection{Tamaño: Forma 2.}

9.0.0.0. Altura de la pieza: $100 \mathrm{~mm}$.

9.0.1. Diámetro máximo: $181 \mathrm{~mm}$.

Relación entre la altura y el diámetro máximo:

$$
\frac{100}{181}: 0.55
$$

\subsection{Tamaño: Forma 3.}

9.0.0.0. Altura de la pieza: $65 \mathrm{~mm}$.

9.0.1. Diámetro máximo: $114 \mathrm{~mm}$.

9.0.0.1. Altura del punto angular: $20 \mathrm{~mm}$.

Relación entre la altura y el diámetro máximo:

$$
\frac{65}{114}: 0.57
$$

9.1. Espesor de las paredes: 4 a $7 \mathrm{~mm}$ del borde a la base.

9.4.0. Borde: Directo, con ligero engrosamiento en varios ejemplares, formas 1 y 3 .

9.4.1. Evertido, en forma gradual por medio de un punto de inflexión, forma 2.
9.5.0./2. Labio: Recto o convexo.

9.6.1/2. Base: Plana-cóncava a convexa-cóncava. La base plana-cóncava de la forma 1 se caracteriza por presentar una pequeña convexidad central en la cara externa, rasgo excepcional en San Pedro de Atacama.

10. Decoración:

10.0. Técnica: Grabado sobre la superficie externa en pasta seca. Algunas piezas tienen las líneas grabadas rellenas con una sustancia blanquecina, al igual que en el tipo Negro Grabado. Los motivos curvilíneos que se dan en la forma 1 son más regulares, probablemente fueron ejecutados en pasta más blanda. Dos vasos de esa forma, uno de ellos de Solor 3 Túmulo Norte-Sur, tumba 458 , muestran sobre el fondo rojo un baño negro muy diluido que cubre las zonas sin grabar de la banda decorativa. Munizaga (1963: 105-106) señala esta variación.

10.1. Motivos: Geométricos rectilíneos y curvilíneos. En todos los ejemplares, al igual que en el Negro Grabado, se presenta como rasgo característico, una guarda horizontal en el borde, formada por un par de líneas onduladas, rombos unidos por los vértices o líneas paralelas verticales. Debajo de ésta se dispone la banda decorativa principal. Los motivos pueden ser: triángulos opuestos por el vértice, rombos rellenos con reticulados (Figura 15), "juego de cola" (sensu Le Paige), dos líneas verticales que terminan en cada extremo en dos círculos concéntricos, similar al motivo que ilustra Munizaga (1963: fig. VIIa) para el tipo San Pedro Negro Sobre Rojo no clasificado. Otras vasijas están adornadas con un motivo curvilíneo de volutas rellenas con puntos (Figura 17).

\section{Observaciones}

En conexión con el tipo Rojo Grabado se halla gran cantidad de fragmentos obtenidos en recolecciones superficiales por el padre Le Paige y Munizaga (1963) en los ayllos del sur, Coyo y Tulor, y descritos por este último.

Con respecto al número de piezas enteras exhumadas de los enterratorios, llama la atención el bajo porcentaje de los tipos Negro y Rojo Grabado con relación a los tipos Negro y Rojo Pulido. Este hecho 


\begin{tabular}{|c|c|c|c|c|c|c|}
\hline \multirow{3}{*}{ Sitios } & \multicolumn{4}{|c|}{ Formas y bases } & \multirow{3}{*}{ Total } & \multirow{3}{*}{ Porc. } \\
\hline & \multicolumn{2}{|c|}{1} & \multirow{2}{*}{$\begin{array}{c}2 \\
\text { Plana-cóncava }\end{array}$} & \multirow{2}{*}{$\begin{array}{c}3 \\
\text { Plana-cóncava }\end{array}$} & & \\
\hline & $\begin{array}{l}\text { Convexa- } \\
\text { cóncava }\end{array}$ & Plana-cóncava & & & & \\
\hline Solor 3 Túmulo Norte-Sur & 2 & 4 & 1 & 2 & 9 & 64.1 \\
\hline Quitor 5 & & 2 & & & 2 & 14.3 \\
\hline Quitor 6 & & 1 & & & 1 & 7.2 \\
\hline Sequitor Oriental & 1 & & & & 1 & 7.2 \\
\hline Larache Callejón & & & 1 & & 1 & 7.2 \\
\hline Total & 3 & 7 & 2 & 2 & 14 & \\
\hline Porcentaje & 21.4 & $\mathbf{5 0}$ & 14.3 & 14.3 & & 100 \\
\hline
\end{tabular}

Cuadro 4. Frecuencias del tipo rojo grabado según sus formas y bases por sitios.

El total de piezas es muy bajo como para proporcionar pocentajes confiables (San Pedro de Atacama, noviembre de 1964).

podría estar indicando la llegada de una tradición de otra área que habría originado estos tipos locales con un desarrollo pobre. Es probable que se deban a una influencia del Noroeste Argentino, por lo menos en parte.

En cuanto a su comportamiento en las tumbas, aparecen asociados al tipo Negro Pulido de formas VII y IV y materiales de influencia tiahuanaco (fases IV y V).

Según el padre Le Paige, el motivo decorativo "juego de cola", asociado a los pucos hemisféricos (formas A y 2, respectivamente) sería más antiguo que los otros diseños.

\section{Otros tipos}

Resulta imposible incluir aquí, por la extensión de este artículo, la descripción detallada de los otros tipos cerámicos obtenidos de las excavaciones en las zonas aledañas al pueblo actual. Entre ellos interesa un tipo que hemos caracterizado como Gris Grueso Pulido sin que esto signifique una denominación, ya que no presentamos una descripción completa. Hemos registrado 86 ejemplares con procedencia de Larache Acequia, Sequitor Alambrado Acequia, Sequitor Alambrado Oriental, Solor 3 Parte Occidental y Túmulo Norte-Sur, Quitor 2, 5, 6 y 7 concentrándose el mayor número de casos en Solor 3 Túmulo Norte-Sur con 24 especímenes y Quitor 6 con 21 casos. Se trata de una cerámica de pasta poco compacta, con antiplástico mediano denso, superficies grises pulidas, cocida en atmósfera reductora con manchas por defectos de cocción. Se pueden distinguir las siguientes formas:

1. Vasijas simples, restringidas, cuerpo subcilíndrico con paredes ligeramente convexas, base plana-cóncava, un asa doble adherida en arco lisa, en posición vertical. Corresponde a la denominación tradicional de taza (Figura 18).

2. Vasijas simples, no restringidas, forma subcónica, base convexa en la cara externa sin diferenciarse netamente del contorno del cuerpo. No poseen asas (Figura 19).

3. Escudillas simples, no restringidas, sección esferoide. Se caracterizan por presentar la superficie interna pulida y la externa alisada, posiblemente con un fin utilitario para la contención de alimentos.

4. Vasos simples, restringidos, cuerpo ovoide con el borde directo o evertido gradualmente.

5. Botellones de silueta inflexionada, boca restringida, cuerpo ovoide, cuello hiperboloide, base convexa-cóncava, sin asas.

6. Cántaros inflexionados, restringidos, cuerpo esferoide, cuello hiperboloide, borde evertido abrupto por medio de un punto angular, dos asas dobles adheridas en arco de posición horizontal.

El espesor de las paredes oscila entre 6 y $10 \mathrm{~mm}$.

Hay coincidencia de rasgos entre esta clase de cerámica y el tipo San Pedro Grisáceo Pulido descrito 
por Munizaga (1963: 120). El comportamiento de este tipo en las asociaciones de tumbas se relaciona con el desarrollo del tipo Negro Pulido superándolo probablemente en el tiempo, hasta épocas más tardías, por medio de la forma de puco 3 .

Llevamos a cabo, también, un análisis de la cerámica ordinaria, grisácea o rojiza, que se conserva en el Museo como producto de las excavaciones. En la mayoría de los casos, las superficies están alisadas, en muy pocos ejemplares, son totalmente irregulares. Se produce un aumento en el tamaño del antiplástico y del espesor de las paredes que, en vasijas de tamaño grande, llega a $10 \mathrm{~mm}$ o más. Dentro de la variedad gris se dan las formas 2, 3, 4 y 5 recién descritas, con dimensiones bastante semejantes a las del grupo gris grueso pulido. La forma 3, pucos en forma de sección de esfera, es el único espécimen cerámico que aparece en muchas tumbas de contexto tardío muy empobrecido culturalmente.

En la variedad de las rojizas, color producto exclusivamente de la cocción, se incluyen vasijas de gran tamaño, de forma inflexionada, boca restringida, ovoides con variaciones. En muchos casos, han sido utilizadas como urnas. Dos de estas vasijas, con procedencia de Solor 6, con la característica de la base cónica o aguzada, han sido postuladas como los representantes cerámicos más tempranos de San Pedro de Atacama (Orellana 1962, 1963a y b; Le Paige 1963a; Núñez 1965). Es interesante la aparición de este tipo de base, no común en el área, que vuelve a darse en algunos ejemplares del Negro Pulido, de forma X $(0.46 \%$ del total $)$.

Otro tipo, adscrito al Período Tardío, es el conocido como "concho de vino" (sensu Le Paige), "San Pedro Roja Violácea" (sensu Orellana), "San Pedro Rojo Pintado" (Núñez 1965: lám. IV, fig. 5). Hacemos votos para que se concrete la unificación de la terminología en torno a este tipo que evitará confusiones en el futuro. Las características más notables son la aplicación de un engobe borravino espeso que deja una capa bien notable sobre las superficies con distinta textura que la pasta, y las formas nuevas, completamente distintas a las de todos los tipos mencionados más arriba. Una de las más típicas es una vasija de contorno complejo con un punto angular que marca la superposición de dos cuerpos y por lo menos dos puntos de inflexión, con dos asas horizontales de doble inserción, por debajo del punto angular (ver Núñez 1965: lám. IV, fig. 5; Le Paige 1957/58: foto 24). Otra forma es un vaso simple, de boca restringida, esférico, base convexa sin diferenciación neta del contorno del cuerpo. Este tipo cerámico se da en Solor 4, 5, Vilama, Solcor, Catarpe, y fragmentos en el Pucara de Quitor. Se distribuye, hacia el norte, en el área del río Loa. Creemos que existe una relación, en el territorio argentino, con tipos tardíos de la Quebrada de Humahuaca que se singularizan por un engobe morado espeso. Las investigaciones de Krapovickas en el borde oriental de la Puna aportarán, sin duda, datos importantes en este sentido. En San Pedro de Atacama esta cerámica se da en la fase VII, que presenta relaciones con Huruquilla, Yura, Tilcara y Yavi (Tarragó 1968: 141).

\section{Consideraciones finales. Relaciones}

Las tradiciones alfareras de San Pedro de Atacama se caracterizan por la elaboración de cerámica exclusivamente monocroma, roja, negra y gris, alcanzando un alto nivel técnico en el caso de la alfarería negra pulida. Nadie que haya visitado el museo de esa localidad puede dejar de admirar la simplicidad y belleza de sus formas, la delgadez de sus paredes y la perfección de sus superficies negras bruñidas. En ella radica uno de los rasgos más sobresalientes de esta zona arqueológica.

El agregado de una decoración modelada o grabada, en cambio, no pasa de ser un intento, bastante pobre y con escaso número relativo de ocurrencias.

Otra característica que surge del análisis es la repetición de las mismas formas generales en los distintos tipos, lográndose la diferenciación por medio del agregado de rasgos, tales como, modificaciones del borde, labio, asas, bases y apéndices. Se observa, además, en general, un predominio de las formas altas (vasos u ollas en el sentido tradicional) sobre las bajas (pucos o escudillas) como se desprende de los cuocientes de relación entre altura y diámetro máximo.

De los totales registrados para cada tipo descrito, resultan proporciones relativas muy llamativas. Mientras el Negro Pulido concentra el $82.20 \%$ de apariciones, el Rojo Pulido sólo alcanza el 11.84\%, el Gris Grueso Pulido, 3.66\%, Negro Grabado, $1.70 \%$ y Rojo Grabado, $0.60 \%$. Las diferencias de porcentajes son notables. Sin lugar a dudas, el Negro Pulido constituye la alfarería funeraria característica de los oasis de San Pedro de Atacama y la tradición alfarera de mayor duración, como lo 
indican los contextos de las numerosas tumbas con Negro Pulido.

Mientras el Negro Pulido es un tipo cerámico evidentemente funerario, es posible que el Rojo Pulido haya tenido su función en la vida diaria. De ahí su menor popularidad en los enterratorios. Pero las diferencias pueden deberse también a la distinta duración de las tradiciones culturales.

Los tipos grabados, aunque muy bien definidos en su morfología, no son tipos representativos de San Pedro de Atacama; su foco de origen debe encontrarse fuera de esa zona. Señalamos más adelante algunas semejanzas con tipos grabados de Argentina.

Aparte de su desarrollo temporal, la alfarería negra pulida manifiesta cierta fuerza expansiva, como lo indica el espacio recorrido hacia el interior del Noroeste Argentino. Aparece en este territorio, en dos sitios en forma indudable. En Tebenquiche, Krapovickas (1955: 21) ha exhumado vasos "cilíndricos" (forma I), "tronco de conos" (forma III), "pucos" hemisféricos (forma IV) de "cerámica totalmente negra, brillante, pulida y quebradiza" que pudimos comparar personalmente y por todos sus rasgos, antiplástico, pasta, color, tratamiento de las superficies, espesor y formas pertenecen al tipo San Pedro Negro Pulido. Ya en aquel entonces, Krapovickas establecía la relación con la alfarería negra de la región atacameña, basándose en los datos proporcionados por Latcham (1928). En el estado actual de los estudios y después de nuestra confrontación con muestras del tipo, pensamos que se trata de piezas importadas, a las que luego, en el momento del enterramiento, se agregó una pintura roja postcocción en forma de bandas verticales (Figura 2). Consideramos de gran importancia este hallazgo que fue la primera señal de una relación en una época en que todavía no se habían iniciado las excavaciones intensivas en San Pedro de Atacama.

Posteriormente y por sugerencia del Dr. Alberto Rex González, hemos podido constatar la aparición de una vasija negra pulida de San Pedro de Atacama en una tumba de la cultura Ciénaga del valle de Hualfín (provincia de Catamarca), perteneciente a la Colección Muñiz Barreto. Se trata de un vaso de forma II, simple, de boca restringida, subcilíndrica, base plana, dos mamelones macizos, borde evertido por medio de ángulo. Creemos que es una pieza importada al igual que los ejemplares de Tebenquiche.
En el camino entre Tebenquiche y Hualfín existe otro sitio que también sugiere relaciones con San Pedro de Atacama. Se trata del sitio de Laguna Blanca (Catamarca), donde los materiales de la Colección Muñiz Barreto, actualmente en estudio por el Dr. González (1960, 1963), ofrecen toda una sucesión cultural desde épocas agroalfareras tempranas hasta prehispánicas tardías. En un grupo de tumbas de ese sitio se da un tipo cerámico negro o gris pulido que, si bien no es exactamente igual al San Pedro Negro Pulido como en los casos anteriores, sugiere, sin duda, una relación con San Pedro de Atacama. Se dan diferencias de pasta y el color negro de las superficies no es tan intenso. Hay en cambio, coincidencias de forma y rasgos asociados, jarros cilíndricos (I) con un asa doble adherida en arco, posición vertical; vasos tronco-cónicos con dos asas dobles adheridas horizontales (III) y escudillas hemisféricas con o sin asas pequeñas dobles adheridas horizontales sobre el borde. En muchos casos, estas asitas no son funcionales, característica típica de la alfarería de San Pedro de Atacama. La cocción ha sido realizada también en atmósfera reductora. Algunas de estas vasijas, sobre todo las cilíndricas de paredes ligeramente convexas, por la menor calidad técnica del acabado de las superficies y el espesor de sus paredes nos recuerdan a los jarros de forma I de la cerámica gris gruesa pulida. Presentan semejanzas, además, con los vasos subcilíndricos que Krapovickas describe para Tebenquiche (1955: 18-19).

Otro indicio de la llegada del tipo Negro Pulido al Noroeste Argentino lo proporcionan los vasos de "cerámica negra de lustre córneo" que publica Serrano (1963) con procedencia de La Poma (Salta). Pertenecen al subtipo negro pulido decorado con decoración B, y, de acuerdo con la foto que acompaña (Figura 19), se trata de piezas importadas. ${ }^{5}$

Por el contrario, no observamos coincidencia de rasgos con la cerámica negra bruñida "de brillo metálico" que publica Ambrosetti (1907) para La

5 Excavaciones que realizamos en el departamento de La Poma en búsqueda de un horizonte alfarero temprano en el valle Calchaqui han proporcionado materiales que sugieren contactos con el área puneña y de San Pedro de Atacama, entre ellos, las pipas acodadas. Además, en relación con la difundida tradición de alfarería monocroma en atmósfera reductora, se da una cerámica negra con estrías de pulimento que, a su vez, presenta similitudes con la descrita por Cigliano (1970) para Las Cuevas. 
Paya (Salta) que, por otra parte, tiene una posición temporal más tardía que la tradición alfarera del negro pulido. Nos interesó, en cambio, al revisar la colección de materiales depositados en el Museo Etnográfico de Buenos Aires, la gran abundancia de pucos grises, hemisféricos o un tercio de esfera, pulidos por dentro, alisados por fuera, posiblemente por razones funcionales. Este tipo de puco, común en otros sitios del norte y en la Quebrada de Humahuaca durante la época tardía, nos recuerdan a los pucos que se dan también en contextos tardíos de los oasis de San Pedro de Atacama (fases VI y VII) (Tarragó 1968).

Con respecto a las influencias llegadas a San Pedro desde el Noroeste Argentino, ya han sido señaladas las culturas de Candelaria, Ciénaga, Aguada y Condorhuasi por González, Le Paige, Orellana y Munizaga durante el Congreso de San Pedro de Atacama en 1963. Nos limitaremos aquí a las siguientes anotaciones.

Aparte de los fragmentos indudables de cerámica Ciénaga y Aguada, incisos, grabados y pintados, que aparecen en San Pedro de Atacama, se ha relacionado la cerámica (San Pedro Inciso) con la cerámica Aguada. Nosotros deseamos modificar un poco esta postulación. Más bien que con la cerámica grabada Aguada típica del valle del Hualfín, creemos que se relaciona con un tipo rojo o negro grabado que se da más al norte, en Salta. Se caracteriza por una forma de puco simple hemisférico o con un punto angular con la superposición de dos troncos de conos, las superficies interna y externa pulidas y base plana-cóncava. La decoración de líneas ásperas ha sido ejecutada por la técnica de grabamiento en pasta seca. Los motivos son siempre geométricos, triángulos superpuestos o unidos por el vértice, reticulados, rombos. Estos motivos se disponen en una banda horizontal sobre la superficie externa por encima del punto angular del contorno, agregándose en el borde una banda más pequeña, formada en la mayoría de los casos por dos líneas horizontales en zigzag. Este tipo se distribuye desde la parte norte del valle de Santa María (Tolombón, Cafayate), continuando por el valle Calchaquí y otros sitios de la región centro-occidental de Salta. También aparece este tipo en la Colección Schreiter con procedencia del departamento de La Candelaria. Entre los fragmentos publicados por Serrano (1963: fig. 14) con procedencia de Ampascachi y Peñas Azules, hay dos o tres que pueden corresponder a este tipo. En la Colección Ambrosetti de La Paya y Pampa Grande, depositada en el Museo Etnográfico de Buenos Aires, hemos encontrado escudillas con decoración grabada que presentan similitudes con los tipos Rojo y Negro Grabado de San Pedro de Atacama. Hay fragmentos de pucos rojo grabados y dos pucos completos de Pampa Grande Nos 132 y 133, que se asemejan notablemente al puco San Pedro Rojo Grabado publicado por (Munizaga 1963: lám. IV, fig. 2) y por nosotros (Figura 20).

González (1960: 314) ha sugerido que podría tratarse de un Candelaria III, perteneciente al Período Medio y en relación con la tradición de cerámica grabada de Aguada, pero con un grado bastante alto de transformación. Heredia, posteriormente, en el minucioso trabajo que ha efectuado con respecto al área y cultura de La Candelaria, menciona la asociación de pucos negros y rojos grabados con estas características en Candelaria III y IV, Facie Rupachico (Heredia 1969).

Otro hecho que debe tener relación con las selvas orientales es la presencia de grandes vasijas llanas, con función de urnas funerarias, que parecen presentarse en épocas tempranas (Solor 6) de las comunidades agroalfareras de San Pedro de Atacama como en épocas tardías, según los datos aportados por Le Paige (1964) para Solor 1, 2, 4, 5 y Sequitor Tchasquir.

Hasta aquí llegamos en nuestro análisis y comentarios. Mucho queda por hacer en relación con la enorme riqueza de las colecciones del Museo de San Pedro de Atacama, entre otros, el análisis detenido del conjunto de ceramios encontrados en las tumbas y que muestran diversas influencias con áreas vecinas, Tiahuanaco, Molle, Loa, Huruquilla, Yura, Tilcara, Yavi, Inca, pero para ello, es necesario también cubrir adecuadamente áreas aledañas, sobre todo puneñas, hasta hoy casi desconocidas, para una adecuada comprensión de los procesos. 


\section{REFERENCIAS CITADAS}

AMBROSETTI, J., 1970. Exploraciones arqueológicas en la ciudad prehistórica de La Paya. Publicaciones de la Sección Antropológica 3. Facultad de Filosofía y Letras, Universidad de Buenos Aires, Buenos Aires.

CIGLIANO, E., 1970. Problemas referentes al sitio arqueológico de Las Cuevas, departamento de Rosario de Lerma, provincia de Salta. Relaciones de la Sociedad Argentina de Antropología, Nueva Serie 5 (1): 99-104.

\section{CONGRESO INTERNACIONAL DE ARQUEOLOGIA DE SAN} PEDRO DE ATACAMA, 1963. Anales de la Universidad del Norte 2.

FORD, J., 1962. Método cuantitativo para establecer cronologías culturales. Unión Panamericana, Manuales Técnicos 3. Washington D.C.

GONZALEZ, A. R., 1960. Nuevas fechas de la cronología arqueológica argentina obtenidas por el método de radiocarbón (IV). Revista del Instituto de Antropología 1: 303-331.

- 1963a. Cultural development in Northwestern Argentina. En Aboriginal cultural development in Latin America: An interpretative review, B. Meggers y C. Evans (Eds.), pp. 103-117. Smithsonian Institution, Washington D.C.

- 1963b. Las tradiciones alfareras del Período Temprano del Noroeste Argentino y sus relaciones con las de las áreas aledañas. Congreso Internacional de Arqueología de San Pedro de Atacama, pp. 49-65. Antofagasta.

HEIZER, R. F. (Ed.), 1959. The archaeologist at work. Harper $\&$ Brothers, Nueva York.

HEREDIA, O. R., 1969. Consideraciones sobre el contexto y la cronología de la cultura Candelaria. Ciencia e Investigación 25 (9): 387-405.

KRAPOVICKAS, P., 1955. El yacimiento de Tebenquiche (Puna de Atacama). Publicaciones del Instituto de Arqueología de la Universidad de Buenos Aires, Buenos Aires.

LATCHAM, R., 1928. La alfarería indígena chilena. Imprenta y Litografía Universo, Santiago.

- 1938. Arqueología de la región atacameña. Universidad de Chile, Santiago.

LE PAIGE, G., 1957/58. Antiguas culturas atacameñas en la cordillera chilena. Anales de la Universidad Católica de Valparaíso 4-5.

_ 1963a. Continuidad o discontinuidad de la cultura atacameña. Congreso Internacional de Arqueología de San Pedro de Atacama, pp. 7-25. Antofagasta.
_ 1963b. La antigüedad de una tumba comprobada por Carbono 14 y el ambiente que la rodea. Revista Universitaria XLVIII (26): 167-176.

— 1964. El precerámico en la cordillera atacameña y los cementerios del Período Agroalfarero de San Pedro de Atacama. Anales de la Universidad del Norte 3.

MONTANE, J., 1963. La alfarería negra pulida. Congreso Internacional de Arqueología de San Pedro de Atacama, pp. 43-46. Antofagasta.

MUNIZAGA, C., 1963. Tipos cerámicos del sitio Coyo en la región de San Pedro de Atacama. Congreso Internacional de Arqueología de San Pedro de Atacama, pp. 99-131. Antofagasta.

NIMO, A. F., 1946. Arqueología de Laguna Honda (Yucat, provincia de Córdoba). Publicaciones del Instituto de Arqueología 15. Imprenta de la Universidad, Córdoba.

NUÑEZ, L., 1965. Desarrollo cultural prehispánico del norte de Chile. Estudios Arqueológicos 1.

ORELlANA, M., 1963a. La cultura de San Pedro. Publicación 17, Centro de Estudios Antropológicos. Santiago.

— 1963b. Problemas de la arqueología de San Pedro de Atacama. Congreso Internacional de Arqueología de San Pedro de Atacama, pp. 29-39. Antofagasta.

— 1964. Acerca de la cronología del complejo cultural de San Pedro de Atacama. Antropología, Revista del Centro de Estudios Antropológicos, año II (2): 96-104.

PRIMERA CONVENCION NACIONAL DE ANTROPOLOGIA, 1966. Primera parte. Publicaciones del Instituto de Antropología, Nueva Serie 1. Universidad Nacional de Córdoba, Córdoba.

SERRANO, A., 1952. Normas para la descripción de la cerámica arqueológica. Publicaciones del Instituto de Arqueología, Lingüística y Folklore 24. Imprenta de la Universidad, Córdoba.

— 1963. Líneas fundamentales de arqueología salteña. Talleres Salesianos, Salta.

SHEPARD, A., 1963. Ceramics for the archaeologist. Publication 608, Carnegie Institution of Washington, Washington D.C.

TARRAGO, M., 1968. Secuencias culturales de la etapa agroalfarera de San Pedro de Atacama (Chile). Actas y Memorias del XXXVII Congreso Internacional de Americanistas, 1966. Buenos Aires. 


\section{APENDICE \\ Informe sobre el estudio petrográfico de muestras cerámicas de San Pedro de Atacama}

Muestra 1 (San Pedro Negro Pulido)

Se trata de una cerámica no muy compacta, especialmente en la parte media. Posee la superficie externa de color negro brillante y homogénea, mientras que la interna es de color negro, opaca y con numerosas irregularidades y poros.

$\mathrm{Al}$ microscopio, presenta las zonas correspondientes a las superficies interna y externa, fuertemente teñida de color rojo oscuro a negro, por óxido de hierro. La coloración no es regular y disminuye hacia el interior de la muestra, distribuyéndose a lo largo de grietas. Ambas zonas poseen una textura peculiar debido a la disposición subparalela de los componentes minerales y por una orientación marcada de grietas, todo ello debido a la acción mecánica de moldeo de la cerámica.

La composición mineralógica puede dividirse en Clastos y Pasta. Los Clastos corresponden a minerales, entre los que se distinguen plagioclasas de composición media (andesina), machadas y con estructura zonal. Ortosa en fragmentos pequeños angulosos, ambos felfaspatos no presentan alteraciones, cuarzo, fragmentos correspondientes a cuarzos de vena y otros con extinción recta. Hornblenda, castaño o verdosa, pleocroica y sin alteraciones. Escasas láminas de biotita y gránulos de óxido de hierro. Todos los fragmentos son angulosos, el tamaño mayor es de $1 \mathrm{~mm}$, mientras que el tamaño medio es de 253 micrones.

Como componente clástico importante por su proporción elevada, se observan fragmentos de un material isótropo, con textura subparalela, correspondiente a rocas arcillosas, las cuales debido a la cocción de la cerámica han vitrificado.

La pasta es de grano fino, compuesta por láminas de color castaño rojizo, correspondientes a la fracción

1 Museo de Ciencias Naturales de La Plata, ARGENTINA. ardua del sedimento utilizado para la realización de la cerámica. La difractometría de rayos X reveló una composición correspondiente a montmorillonita, contraída por calcinación.

La parte externa e interna de la cerámica, está compuesta por una serie de capas de un espesor no mayor a $1 \mathrm{~mm}$; fácilmente separable del resto de la cerámica y que al microscopio se identificó como láminas de hematita (var. especularita) unidas por un material ligante, muy escaso.

\section{Muestra 2 (San Pedro Negro Pulido)}

Muy similar en sus características megascópicas a la muestra anterior, pero presenta una textura particular indicadora de un mayor proceso de cocción. El fragmento estudiado es de menor espesor que el de la muestra 1. La orientación de los minerales es muy marcada, observándose al mismo tiempo una fuerte coloración rojo oscuro en toda la muestra y negra en los bordes. Las grietas subparalelas a las paredes de la cerámica son muy numerosas. Debe destacarse que los fragmentos de arcillas vitrificadas presentan mayor irregularidad y en partes ramificaciones, penetrando el material isótropo a lo largo de las grietas. Es común que a su vez envuelvan fragmentos de minerales.

Muestra correspondiente a la cerámica con inscripciones

Es en todo similar a la muestra 1. Es evidente que estas muestras poseen una arcilla, posiblemente alcalina, que sirvió de esqueleto a la cerámica; de tipo montmorillonítico con plasticidad y contracción elevada corresponde a la pasta usada como aglomerante. La hematita puede ser agregada sobre bizcocho (barro cocido poroso) y empastada con agua y quizás algo de bórax como ligante, pues no se observa material extraño entre las laminillas de especularita. Este hecho sería factible, pues en el norte de Chile es fácil obtener este material de las borateras. 


\section{Muestra 3 (San Pedro Rojo Pulido)}

Cerámica roja con superficie homogénea, la exterior se encuentra pintada de rojo. La textura es poco compacta y no se observan grietas ni ordenamiento alineado de los minerales; la composición mineralógica es la siguiente: predominan las plagioclasas, de composición andesina, macladas y zonadas. Cuarzo límpido, hornblenda verde y gránulos de óxido de hierro. Se observan clastos de material arcilloso vitrificado. La forma de los clastos es redondeada a subredondeada. La pasta se halla formada por arcilla en láminas teñidas de rojo.

\section{Muestra 4 (San Pedro Rojo Pulido)}

Es similar a la muestra anterior, pero con una textura más compacta y cierta orientación en sus componentes. Hay una mayor proporción de clastos de arcilla vitrificados, que llegan a envolver parte de los minerales. La pasta se encuentra teñida de color rojo muy oscuro.

La Plata, junio de 1966.

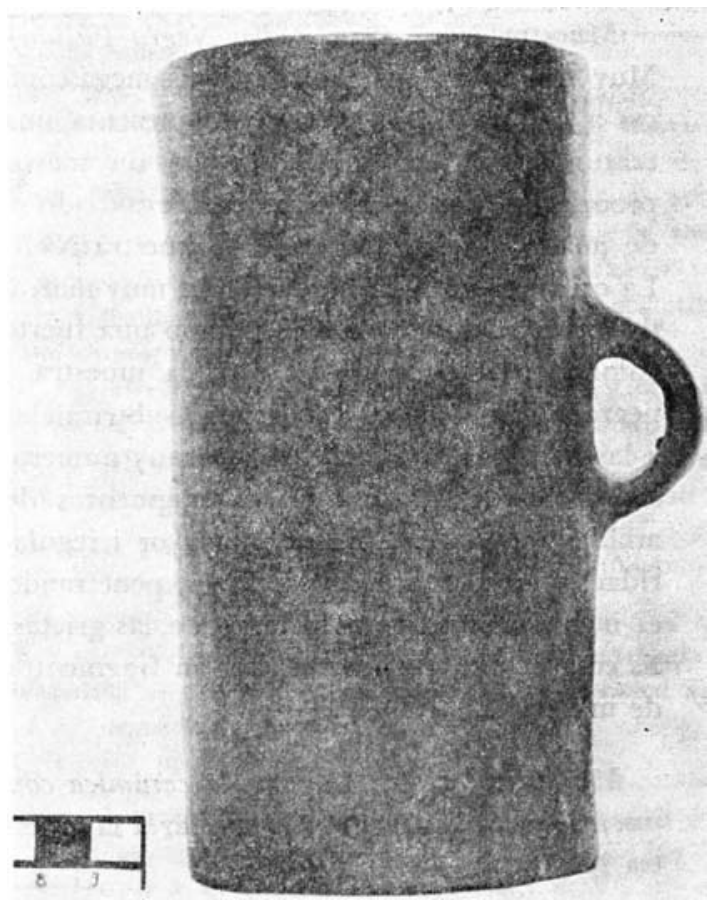

Figura 1. San Pedro Negro Pulido, forma I. Sequitor Alambrado Acequia.

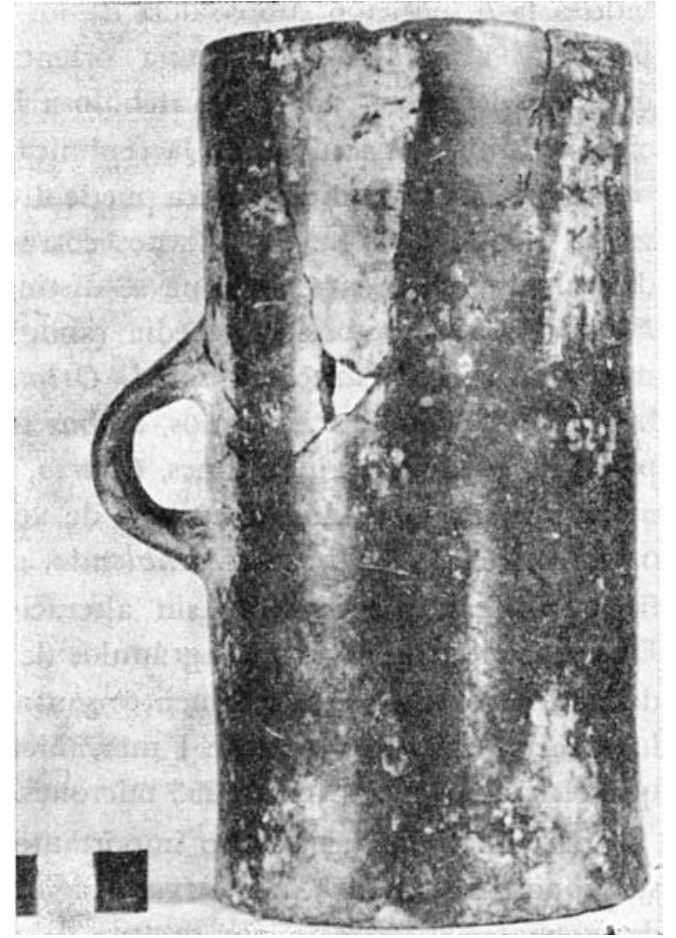

Figura 2. Jarro Negro Pulido, forma I con bandas verticales rojas postcocción. Tebenquiche, Argentina.

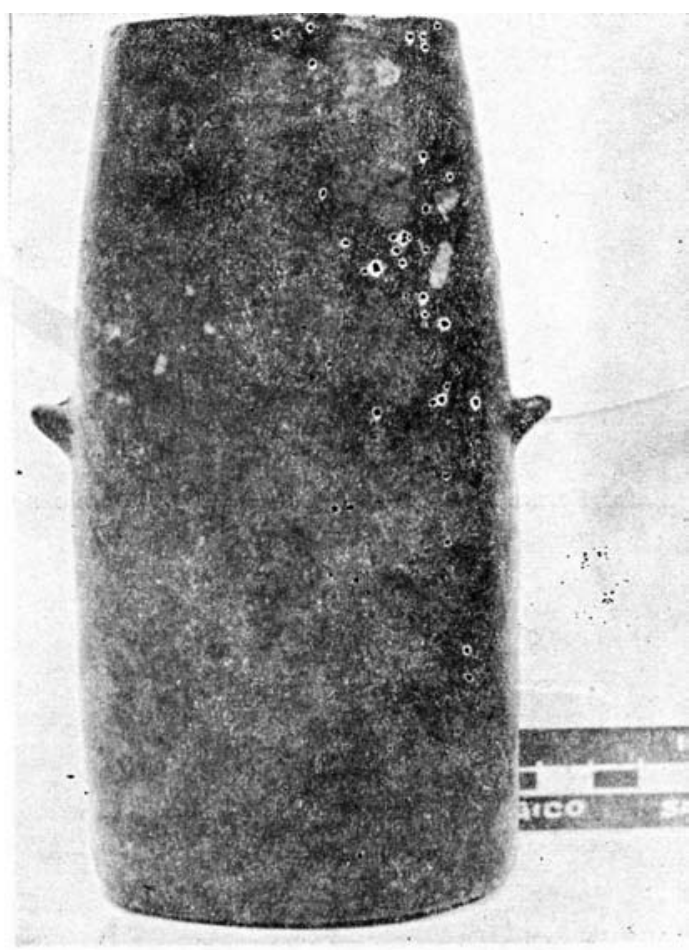

Figura 3. San Pedro Negro Pulido, forma II. Sequitor Alambrado Acequia. 


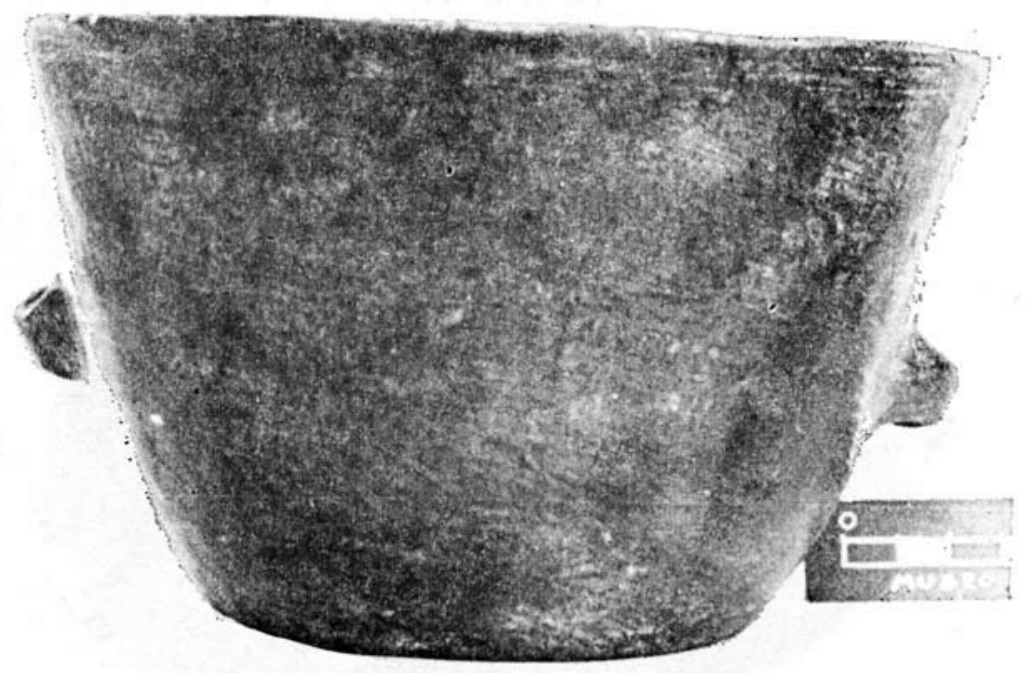

Figura 4. San Pedro Negro Pulido, forma III. Quitor 8.

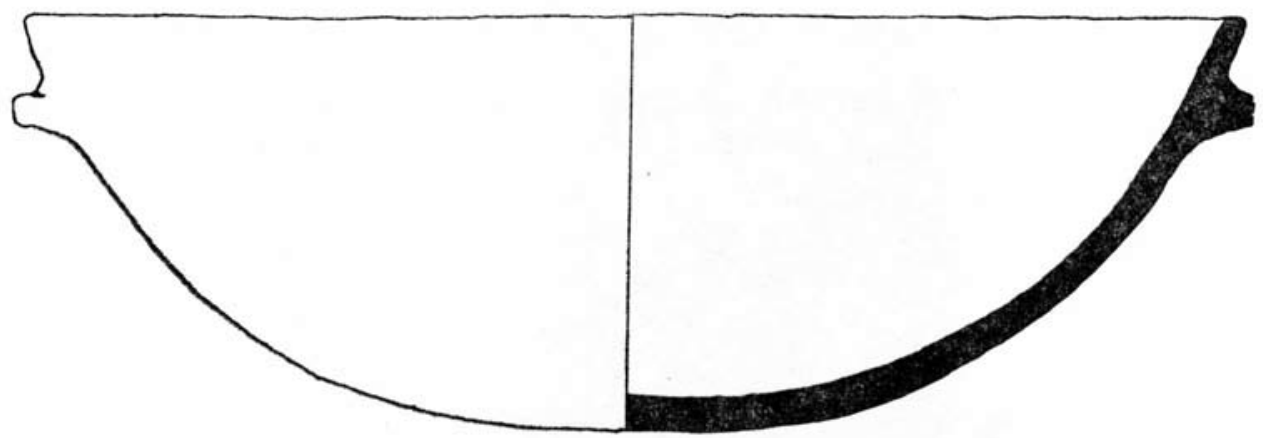

Figura 5. San Pedro Negro Pulido, forma IV (1/2 tamaño natural). Larache Callejón.

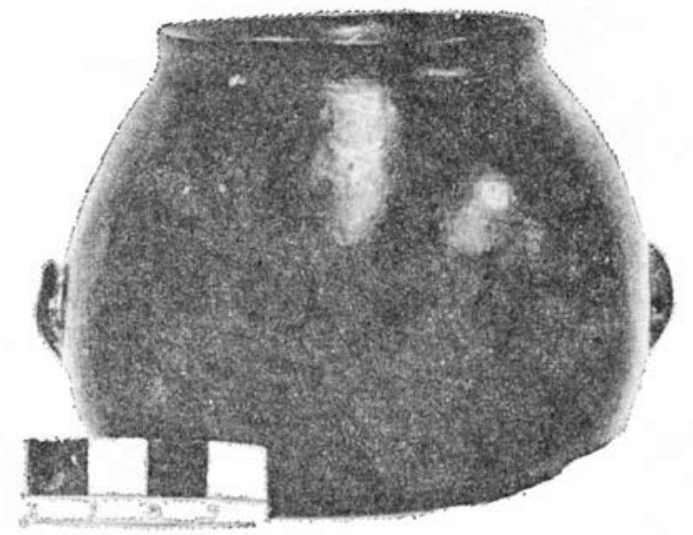

Figura 6. San Pedro Negro Pulido, forma VII. Sequitor Alambrado Acequia. 


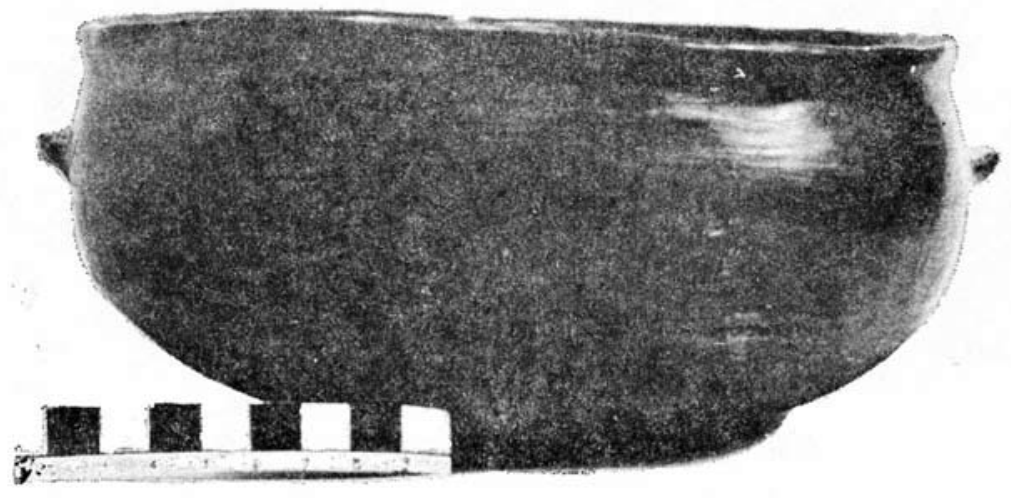

Figura 7. San Pedro Negro Pulido, forma IX. Quitor 5.

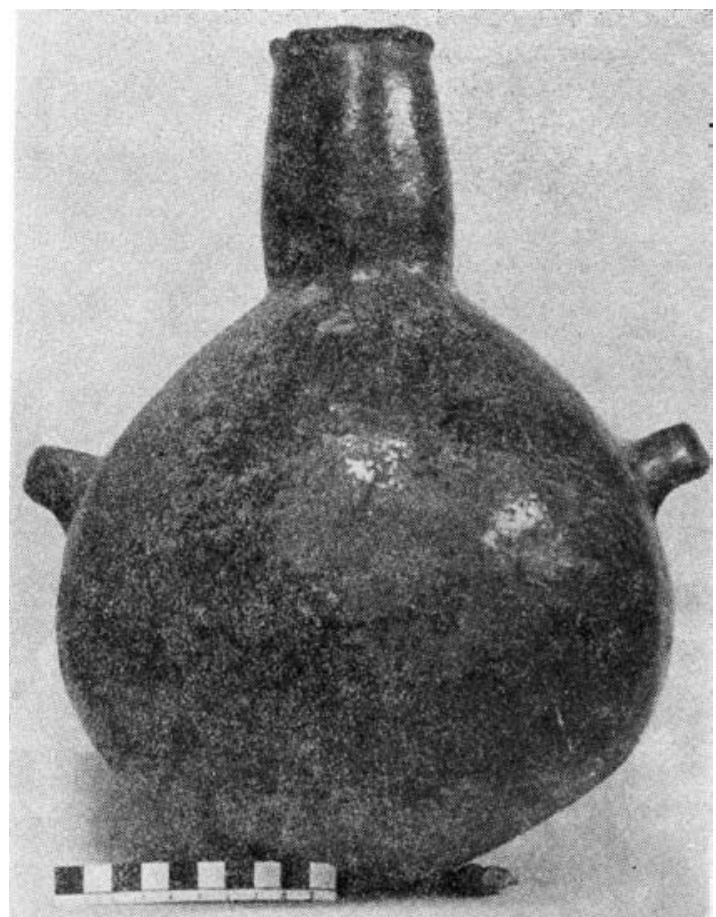

Figura 8. San Pedro Negro Pulido, forma X. Quitor 6.

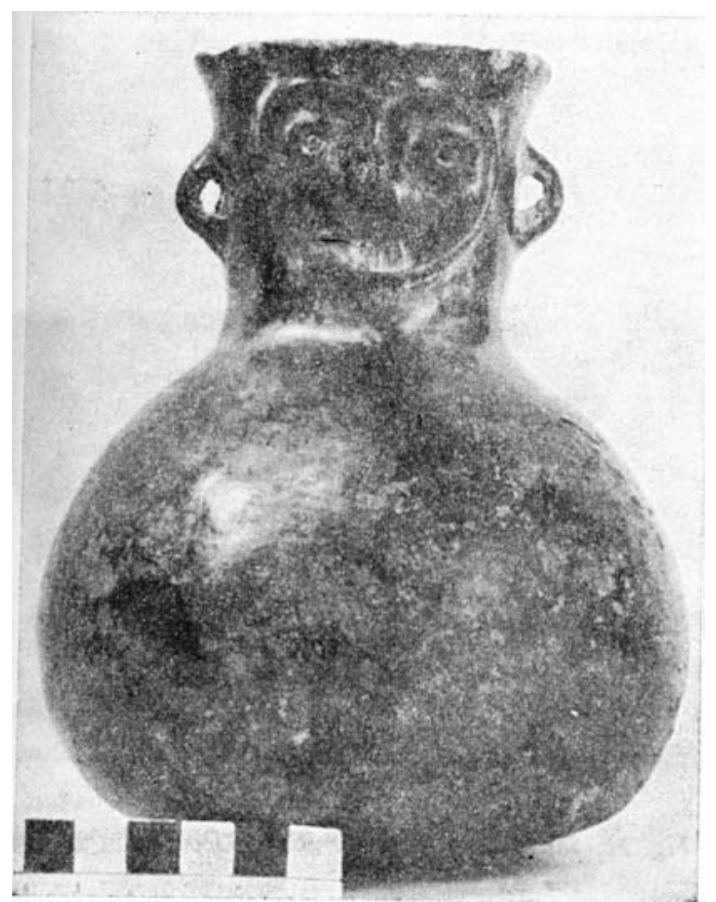

Figura 9. San Pedro Negro Pulido, decoración A. Quitor 7. 


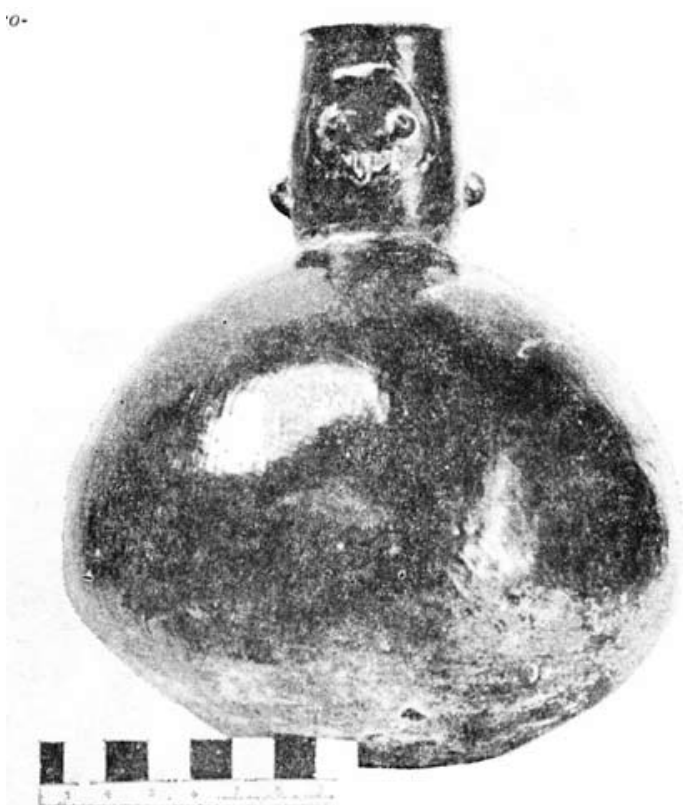

Figura 10. San Pedro Negro Pulido, transición a decoración B. Quitor 6.

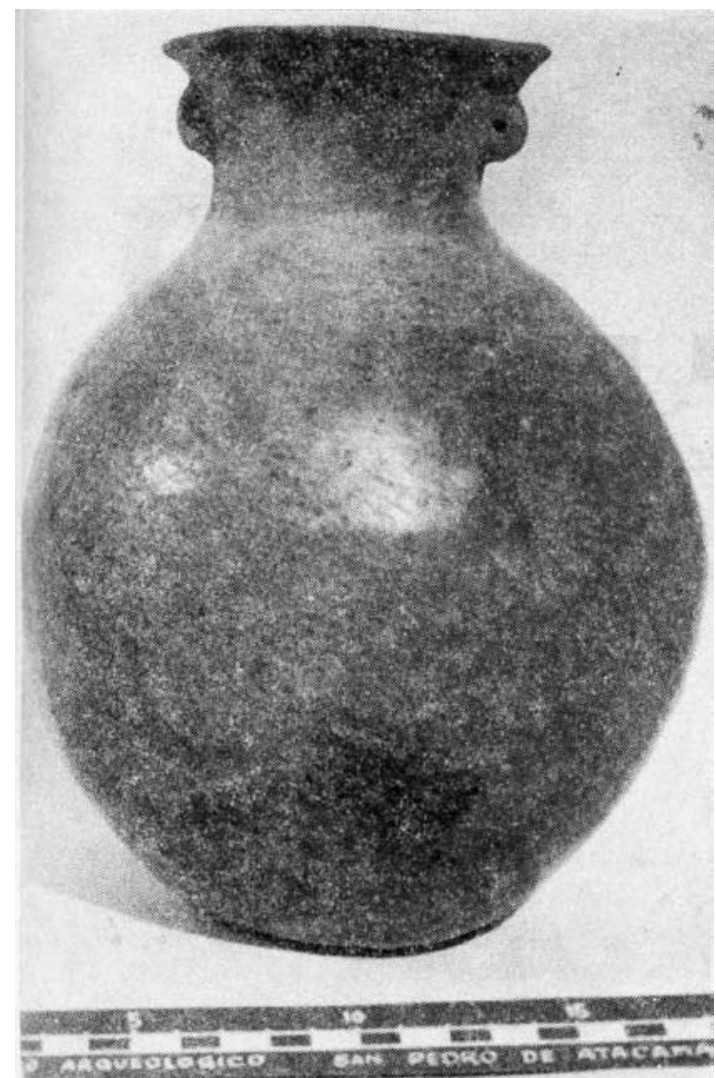

Figura 12. San Pedro Negro Pulido. Sequitor Alambrado Acequia.

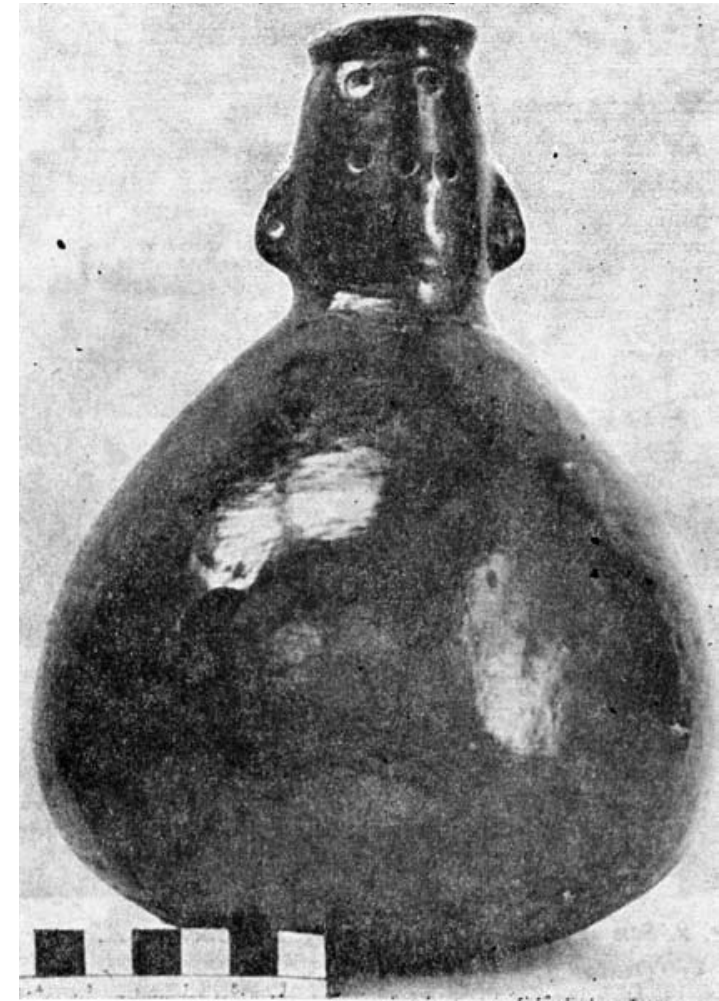

Figura 11. San Pedro Negro Pulido, decoración B. Quitor 6.

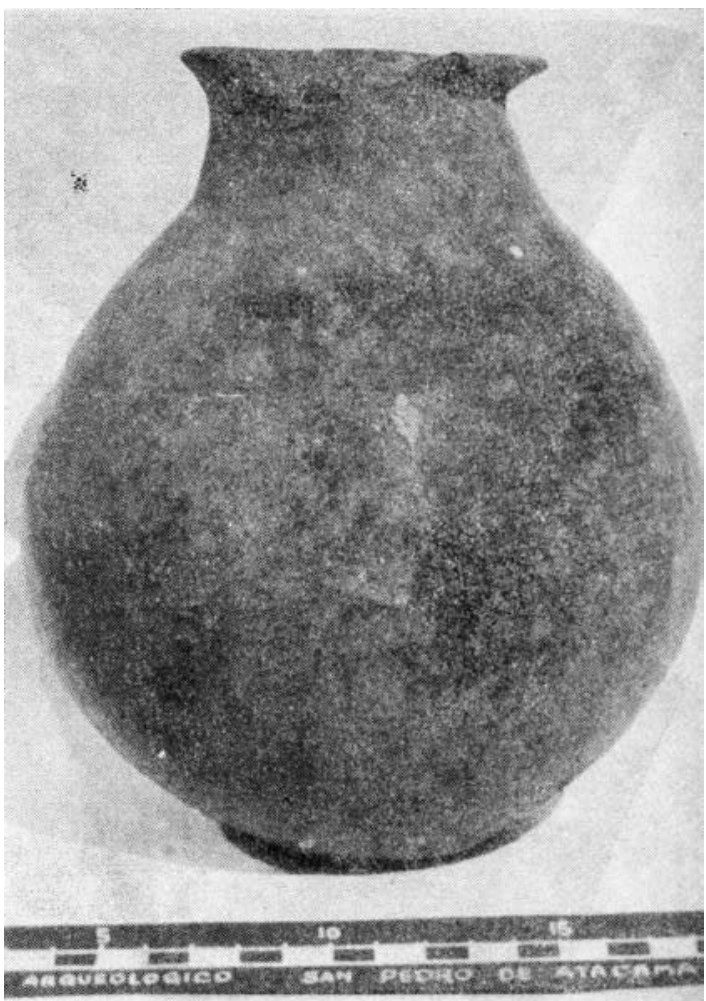

Figura 13. Vasija Gris Pulida con una capa rojiza posterior a la cocción. Solor 3, Parte Occidental. 


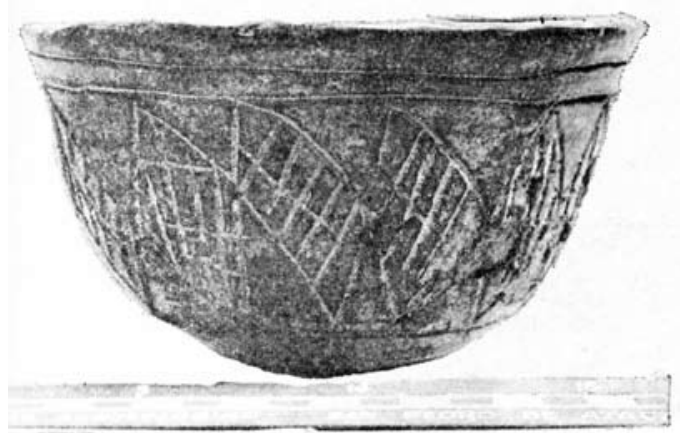

Figura 14. San Pedro Negro Grabado, forma A. Quitor 8, 3180.

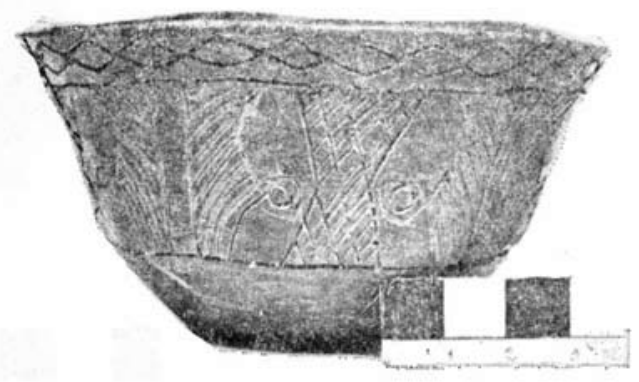

Figura 15. San Pedro Rojo Grabado, forma 3. Solor 3, 455.

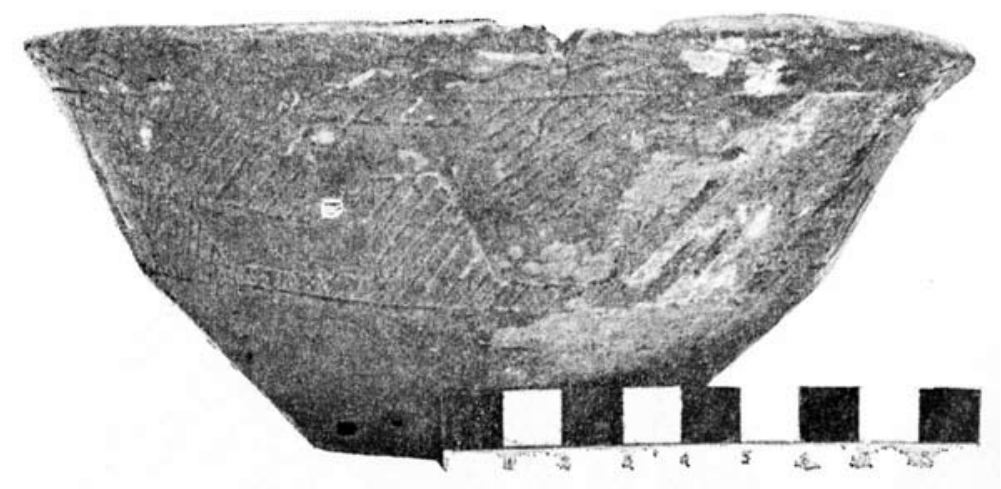

Figura 16. San Pedro Rojo Grabado, forma 3. Solor 3, Túmulo Norte-Sur.

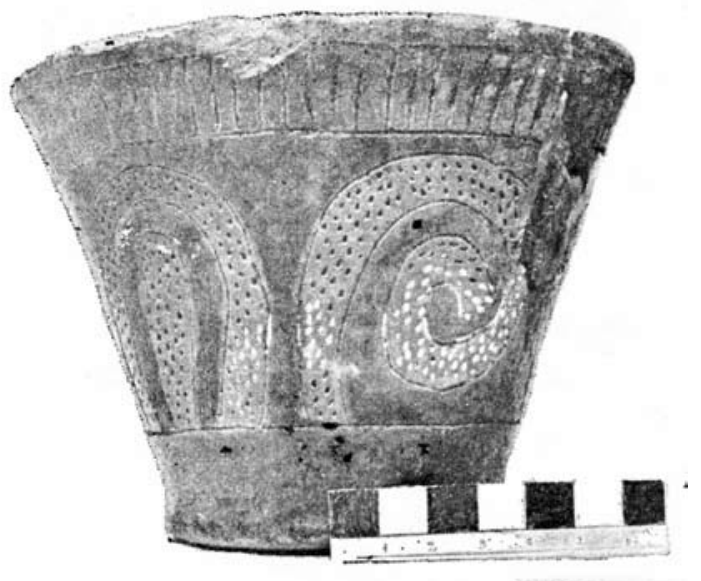

Figura 17. San Pedro Rojo Grabado, forma 1. Solor 3, Túmulo Norte-Sur, 458.

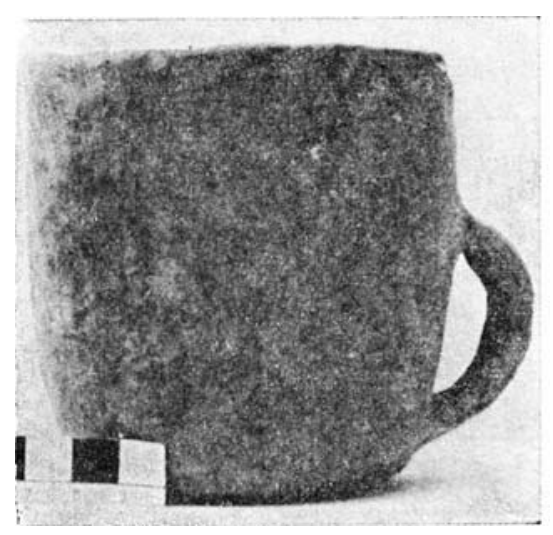

Figura 18. Jarro subcilíndrico Gris Pulido, base cóncava-convexa. Quitor 6 . 


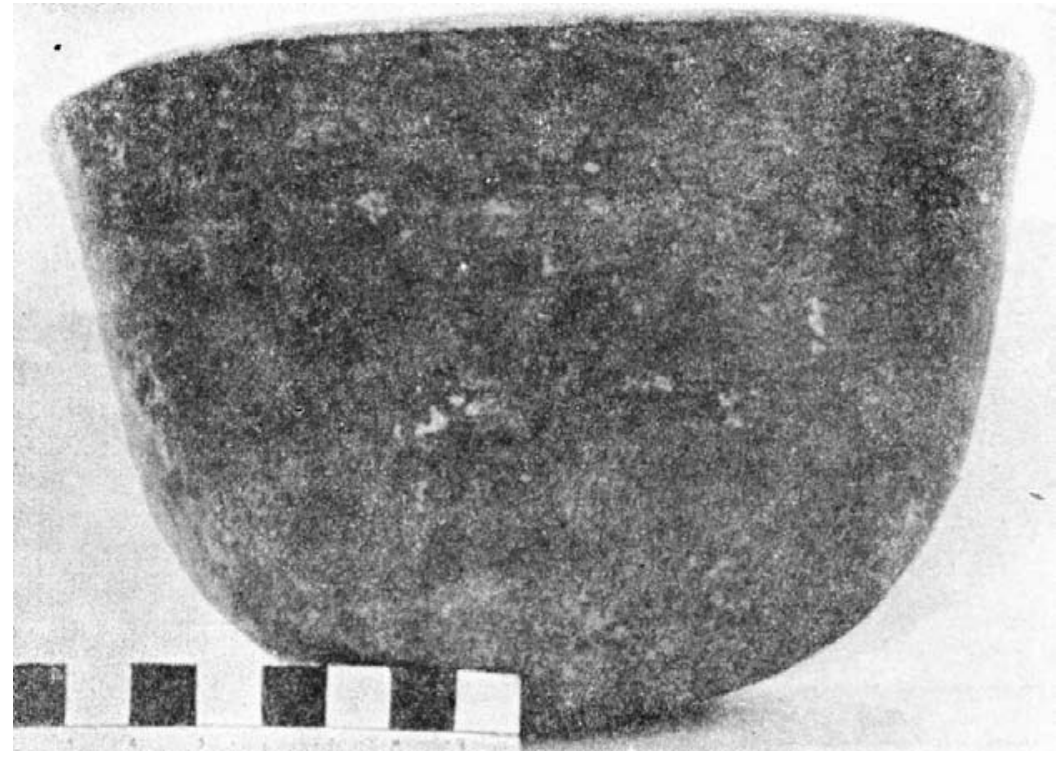

Figura 19. Vasija Gris Pulida simple, base convexa-cóncava. Sequitor Oriental.

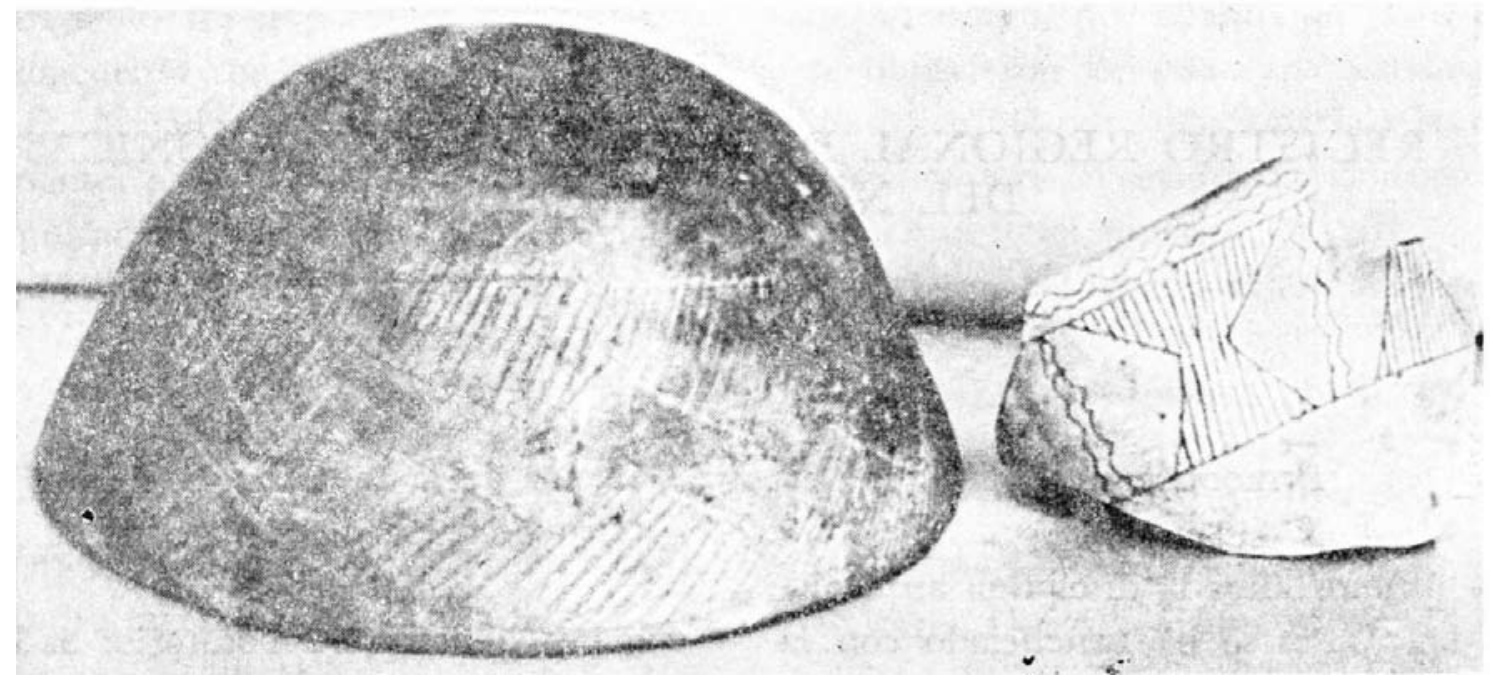

Figura 20. Puco Gris Grabado y un fragmento de un puco Rojo Grabado semejante a la forma 3 del tipo San Pedro Rojo Grabado. Tolombón y Pampa Grande, Argentina. 